\title{
Characterisation of Engineered Nanomaterials in Nano-Enabled Products Exhibiting Priority Environmental Exposure
}

\author{
Raisibe Florence Lehutso ${ }^{1,2}$, Yolanda Tancu ${ }^{1}$, Arjun Maity ${ }^{2,3}$ and Melusi Thwala ${ }^{1,4, *(D)}$ \\ 1 Water Centre, Council for Scientific and Industrial Research, Pretoria 0001, South Africa; \\ FLehutso@csir.co.za (R.F.L.); ytancu@csir.co.za (Y.T.) \\ 2 Department of Chemical Sciences, University of Johannesburg, Johannesburg 2006, South Africa; \\ AMaity@csir.co.za \\ 3 DST/CSIR, Centre for Nanostructure and Advanced Materials (CeNAM), Council for Scientific and Industrial \\ Research, Pretoria 0001, South Africa \\ 4 Department of Environmental Health, Nelson Mandela University, Port Elizabeth 6031, South Africa \\ * Correspondence: mthwala@csir.co.za; Tel.: +27-12-841-3859
}

Citation: Lehutso, R.F.; Tancu, Y.; Maity, A.; Thwala, M. Characterisation of Engineered Nanomaterials in Nano-Enabled Products Exhibiting Priority Environmental Exposure. Molecules 2021, 26, 1370. https://doi.org/ $10.3390 /$ molecules 26051370

Academic Editor: Derek J. McPhee

Received: 30 November 2020 Accepted: 25 December 2020 Published: 4 March 2021

Publisher's Note: MDPI stays neutral with regard to jurisdictional clai$\mathrm{ms}$ in published maps and institutional affiliations.

Copyright: (C) 2021 by the authors. Licensee MDPI, Basel, Switzerland. This article is an open access article distributed under the terms and conditions of the Creative Commons Attribution (CC BY) license (https:// creativecommons.org/licenses/by/ $4.0 /)$.

\begin{abstract}
Analytical limitations have constrained the determination of nanopollution character from real-world sources such as nano-enabled products (NEPs), thus hindering the development of environmental safety guidelines for engineered nanomaterials (ENMs). This study examined the properties of ENMs in 18 commercial products: sunscreens, personal care products, clothing, and paints-products exhibiting medium to a high potential for environmental nanopollution. It was found that 17 of the products contained ENMs; 9, 3, 3, and 2 were incorporated with $\mathrm{nTiO}_{2}, \mathrm{nAg}$, binaries of $\mathrm{nZnO}+\mathrm{nTiO}_{2}$, and $\mathrm{nTiO}_{2}+\mathrm{nAg}$, respectively. Commonly, the $\mathrm{nTiO}_{2}$ were elongated or angular, whereas $\mathrm{nAg}$ and $\mathrm{nZnO}$ were near-spherical and angular in morphology, respectively. The size ranges (width $\times$ length) were 7-48 $\times 14-200,34-35 \times 37-38$, and 18-28 nm for nTiO $\mathrm{nZnO}$, and nAg respectively. All ENMs were negatively charged. The total concentration of Ti, $\mathrm{Zn}$, and $\mathrm{Ag}$ in the NEPs were $2.3 \times 10^{-4}-4.3 \%, 3.4-4.3 \%$, and $1.0 \times 10^{-4}-11.3 \times 10^{-3} \%$, respectively. The study determined some key ENM characteristics required for environmental risk assessment; however, challenges persist regarding the accurate determination of the concentration in NEPs. Overall, the study confirmed NEPs as actual sources of nanopollution; hence, scenario-specific efforts are recommended to quantify their loads into water resources.
\end{abstract}

Keywords: nano-enabled products; engineered nanomaterials; exposure potential; characterisation

\section{Introduction}

Engineered nanomaterials (ENMs) are a case of emerging contaminants and can be emitted from nano-enabled products (NEPs) into water systems. Hence, it is essential to establish the physico-chemical properties of ENMs incorporated in NEPs in order to appropriately examine the environmental exposure potential and implications that may arise across the lifecycle of the products [1]. While the reporting on NEPs' market penetration dates back to 2004 [2,3], the identities and physico-chemical properties of the incorporated ENMs are not well known as they are not commonly reported by manufacturers or the information is very minimal [4,5]. For example, in the Woodrow Wilson International Centre for Scholars and the Project on Emerging Nanotechnology Inventory [6], the incorporated ENMs' types and respective physico-chemical properties are unknown in 49 to $60 \%$ of the listed NEPs $[2,5,7]$.

In the pursuit of addressing the health, safety, and environmental concerns linked to ENMs, it is paramount to gain insights into the properties of ENMs across potential nanopollution sources, including NEPs. However, the relatively minimal efforts of this nature have experienced analytical challenges due to inadequate and non-standardised techniques to characterise ENMs in complex matrices of NEPs [8]. For instance, a technique 
such as single-particle inductively coupled plasma mass spectrometry (spICP-MS) has only been recently developed for the detection and size characterisation of metal-based ENMs in environmental samples [9-11], but it may still not be the best fit to quantify and characterise ENMs in NEPs [12,13], for instance, if sample preparation is not tailored efficiently. Similarly, the commonly applied dynamic light scattering technique for the hydrodynamic size determination of ENMs in suspension also has its limitations [14,15] (e.g., prone to influence by larger size particles). Lastly, some of the relatively efficient techniques are not common pieces of equipment in general environmental laboratories.

Nonetheless, advances have been made in this niche of research despite the persisting analytical challenges, resulting in better knowledge and understanding of the characteristics of ENMs in NEPs [16-27]. Overall, the literature indicates that the ENMs type, quantities, and characteristics in NEPs tend to vary widely even for closely related product types. For example, the commonly incorporated $\mathrm{nTiO}_{2}$ in sunscreens vary in morphology (elongated, angular, irregular), size (18 to $90 \mathrm{~nm})$, surface area $\left(9.1\right.$ to $\left.60.8 \mathrm{~m}^{2} / \mathrm{g}\right)$, and phase (rutile, anatase, or both) properties [17-19,28-30]. Hence, it is not simple to make solid assumptions and estimations based on a few studies, but rich datasets need to be developed in order to strengthen modeling exercises used to predict the environmental fate and effects of ENMs released from NEPs.

The NEPs' environmental exposure potential for ENMs (likelihood to nanopollute) is a critical determinant factor for the environmental fate and effects of ENMs [31]. However, the varying factors such as release potential on ENMs suspended in liquids, surfacebound, solid, or nanostructured influences the exposure potential. [5,31]. Aquatic environments are most likely to experience medium to high exposure extent from NEPs whose ENMs are suspended in liquids, followed by surface-bound [18,32]. Different global inventories $[5,18]$ indicate that NEPs categorised as having medium to high release potential to aquatic environments are common in markets and as much as 36-96\% of the NEPs are being sold. These NEPs are in the product categories of health and fitness (e.g., personal care products, sunscreens, cosmetics) as well as home and garden (cleaning products, paints, laundry cleaning products) $[5,7,18]$. From the different NEPs categories, sunscreens are the most widely studied [17-21,23-26], despite the evidence of high ENMs' environmental exposure potential in NEPs such as paints [33-37] and other personal care products/cosmetics (e.g., toothpaste, shampoos, and face creams) [38,39]. While $\mathrm{nTiO}_{2}$ can be expected to be emitted at relatively higher volumes due to their wide application in a spectrum of NEPs, the incorporation of other ENM types such as $\mathrm{nAg}, \mathrm{nSiO}_{2}$, and $\mathrm{nZnO}$ have been reported in other market active NEPs within the health and fitness, as well as home and garden categories $[7,18,32]$. Due to various facets of data required, other key environmental exposure determinants, for instance, market parameters and life cycle dynamics, tend to be more complex to examine.

The data for ENMs' properties are not readily suitable for direct cross-application for environmental exposure and toxicity assessments even within and across NEPs categories [40-42]; hence, the data generation needs expansion to other types of top-selling commercial NEPs, especially those exhibiting medium to high likelihood for the release of ENMs (i.e., nanopollution). As such, the current study aimed to determine the characteristics of the ENMs for a wide array of commercial NEPs product categories. The studied products were manufacturer-labelled to be NEPs and considered to exhibit medium to high environmental exposure potential for ENMs for water systems [18,32]. Additionally, products suspected to be incorporated with ENMs, either based on product description, or due to similarity to previously identified NEPs, but still meeting the criteria of medium to high environmental exposure, were also included in the study samples. The "suspect" products were included to demonstrate that NEPs may extend wider than the products declared by manufacturers, and hence potentially a greater nanopollution extent than currently estimated. The "suspect products" have previously not attracted attention in ENMs exposure assessments mainly because of the lack of a nano declaration or labelling by manufacturers. The study focused on some top-priority ENMs' parameters for risk 
characterisation data requirements [43], specifically the particle size distribution, shape, phase, surface charge, composition, and concentration. Overall, the study was exclusive to top priority NEPs' potential sources for nanopollution in water systems.

\section{Materials and Methods}

\subsection{Selection of NEPS}

Eighteen products from the health and fitness, home and garden product categories were purchased from South African retailers, as shown in Table 1.

Table 1. The sample of nano-enabled products (NEPs) examined. ${ }^{a}$ and ${ }^{b}$ respectively indicate suspect products and engineered nanomaterials (ENMs).

\begin{tabular}{|c|c|c|c|c|}
\hline Sample & $\begin{array}{l}\text { Product } \\
\text { Type }\end{array}$ & $\begin{array}{c}\text { ENMs Type } \\
\text { (Labelled/Suspected }^{b} \text { ) }\end{array}$ & $\begin{array}{l}\text { ENMs } \\
\text { Location }\end{array}$ & $\begin{array}{c}\text { Ingredient } \\
\text { Description/NEPs } \\
\text { Functionality } \\
\text { Declaration }\end{array}$ \\
\hline SUN1 & Sunscreen & $\mathrm{TiO}_{2}+\mathrm{ZnO}$ & $\begin{array}{l}\text { Suspended in } \\
\text { liquid }\end{array}$ & $\begin{array}{l}\text { Reflective sun protection } \\
\text { (UVA/ UVB) }\end{array}$ \\
\hline SUN2 & Sunscreen & $\mathrm{TiO}_{2}$ & $\begin{array}{l}\text { Suspended in } \\
\text { liquid }\end{array}$ & $\begin{array}{l}\text { UVA/UVB immediate } \\
\text { protection }\end{array}$ \\
\hline SUN3 & Sunscreen & $\mathrm{TiO}_{2}$ & $\begin{array}{l}\text { Suspended in } \\
\text { liquid }\end{array}$ & $\begin{array}{l}\text { UVA/UVB immediate } \\
\text { protection }\end{array}$ \\
\hline SUN4 & Sunscreen & $\mathrm{TiO}_{2}$ & $\begin{array}{l}\text { Suspended in } \\
\text { liquid }\end{array}$ & $\begin{array}{l}\text { UVA/UVB immediate } \\
\text { protection }\end{array}$ \\
\hline SUN5 ${ }^{\text {a }}$ & Sunscreen & $\mathrm{TiO}_{2}+\mathrm{ZnO}^{\mathrm{b}}$ & $\begin{array}{l}\text { Suspended in } \\
\text { liquid }\end{array}$ & Advanced sun protection \\
\hline LB1 & Lip balm & $\mathrm{TiO}_{2}+\mathrm{ZnO}$ & $\begin{array}{l}\text { Suspended in } \\
\text { liquid }\end{array}$ & $\begin{array}{c}\text { Reflective sun protection } \\
\text { (UVA/ UVB) }\end{array}$ \\
\hline $\mathrm{CA} 1^{\mathrm{a}}$ & $\begin{array}{l}\text { Body } \\
\text { cream }\end{array}$ & $\mathrm{Ag}^{\mathrm{b}}$ & $\begin{array}{l}\text { Suspended in } \\
\text { liquid }\end{array}$ & $\begin{array}{c}\text { Ionic colloidal silver, } \\
\text { antibacterial }\end{array}$ \\
\hline $\mathrm{CA} 2^{\mathrm{a}}$ & $\begin{array}{l}\text { Body } \\
\text { cream }\end{array}$ & $\mathrm{Ag}^{\mathrm{b}}$ & $\begin{array}{l}\text { Suspended in } \\
\text { liquid }\end{array}$ & $\begin{array}{l}\text { Ionic colloidal silver, } \\
\text { anti-inflammatory }\end{array}$ \\
\hline CM1 & $\begin{array}{l}\text { Cream } \\
\text { activator }\end{array}$ & $\mathrm{SiO}_{2}$ & $\begin{array}{l}\text { Suspended in } \\
\text { liquid }\end{array}$ & Nano \\
\hline SAN1 ${ }^{\text {a }}$ & Sanitiser & $\mathrm{Ag}^{\mathrm{b}}$ & $\begin{array}{l}\text { Suspended in } \\
\text { liquid }\end{array}$ & $\begin{array}{c}\text { Ionic colloidal silver, } \\
\text { antibacterial }\end{array}$ \\
\hline SAN2 ${ }^{a}$ & Sanitiser & $\mathrm{Ag}^{\mathrm{b}}$ & $\begin{array}{l}\text { Suspended in } \\
\text { liquid }\end{array}$ & Colloidal silver \\
\hline SAN3 ${ }^{\text {a }}$ & Sanitiser & $\mathrm{Ag}^{\mathrm{b}}$ & $\begin{array}{l}\text { Suspended in } \\
\text { liquid }\end{array}$ & Antibacterial \\
\hline PA $1^{a}$ & Paint & $\mathrm{Ag}, \mathrm{TiO}_{2}, \mathrm{ZnO}, \mathrm{SiO}_{2}{ }^{\mathrm{b}}$ & $\begin{array}{l}\text { Suspended in } \\
\text { liquid }\end{array}$ & Nanotechnology \\
\hline $\mathrm{PA} 2^{\mathrm{a}}$ & Paint & $\mathrm{Ag}, \mathrm{TiO}_{2}, \mathrm{ZnO}, \mathrm{SiO}_{2}{ }^{\mathrm{b}}$ & $\begin{array}{l}\text { Suspended in } \\
\text { liquid }\end{array}$ & Nanotechnology \\
\hline $\mathrm{PA} 3^{\mathrm{a}}$ & Paint & $\mathrm{Ag}, \mathrm{TiO}_{2}, \mathrm{ZnO}, \mathrm{SiO}_{2}{ }^{\mathrm{b}}$ & $\begin{array}{l}\text { Suspended in } \\
\text { liquid }\end{array}$ & Antibacterial \\
\hline PA4 ${ }^{\mathrm{a}}$ & Paint & $\mathrm{Ag}, \mathrm{TiO}_{2}, \mathrm{ZnO}, \mathrm{SiO}_{2}{ }^{\mathrm{b}}$ & $\begin{array}{l}\text { Suspended in } \\
\text { liquid }\end{array}$ & New technology \\
\hline PA5 ${ }^{\mathrm{a}}$ & Paint & $\mathrm{Ag}, \mathrm{TiO}_{2}, \mathrm{ZnO}, \mathrm{SiO}_{2}{ }^{\mathrm{b}}$ & $\begin{array}{l}\text { Suspended in } \\
\text { liquid }\end{array}$ & Advanced technology \\
\hline SK1 & Socks & $\mathrm{AgCl}$ & Surface bound & Nano, antibacterial \\
\hline
\end{tabular}

\subsubsection{Characterisation of ENMs}

The physico-chemical characteristics of ENMs obtained from the NEPs were determined using scanning electron microscopy coupled to energy-dispersive X-ray (SEM-EDX), high-resolution transmission electron microscopy coupled with energy-dispersive (TEMEDX), dynamic light scattering (DLS), and X-ray powder diffraction (XRD).

The particle shape, size, and elemental composition were determined using SEMEDX and TEM-EDX. For SEM-EDX (ZEISS Supra55, Oberkochen, Germany) analysis, a small amount of the sample was deposited onto the double-sided carbon tape, which was mounted on a copper stub. The samples were sputter-coated with carbon using a Turbo carbon evaporator (EMITECH-K950X, London, United Kingdom) to prevent 
charging during SEM-EDX analysis. For TEM-EDX (JEOL-JEM 2100, Tokyo, Japan), nTiO $\mathrm{nSiO}_{2}, \mathrm{nZnO}$ and $\mathrm{nAg}$-based samples were respectively dispersed in ethanol $(95 \%$, Merck, Johannesburg, South Africa) and Milli-Q water (18 M $2 . \mathrm{cm})$. The samples were sonicated in a water bath (Ultrasonic bath RK 514 BH cap, Labotec, Johannesburg, South Africa) for $5 \mathrm{~min}$. The $\mathrm{Cu}$ grid with a holey carbon film was dipped into the sample solution multiple times and air-dried for $12 \mathrm{~h}$. Image J software was used to calculate the size of the particles.

The ENMs' zeta potential was determined using DLS (Malvern Zetasizer Nano ZS, Worcestershire, United Kingdom). First, $5 \mathrm{mg}$ of the sample extract (SUN1-5, LB1, CA1-2, CM1, PA1-5, SK1) was dispersed in $10 \mathrm{~mL}$ of Milli-Q water and sonicated for $5 \mathrm{~min}$ in a sonication bath at $25^{\circ} \mathrm{C}$. SAN1 and SAN2 were analysed as purchased. All suspensions were filtered using a $0.45 \mu \mathrm{m}$ syringe filter (Merck, Johannesburg, South Africa) and analysed for zeta potential at $25^{\circ} \mathrm{C}$.

The ENMs' phase was determined using XRD (PANalytical XPERT-PRO diffractometer, Malvern, United Kingdom). Briefly, the samples were deposited on a sample holder and analysed using the XRD diffractometer equipped with $\mathrm{Cu} \mathrm{K} \alpha$ radiation $(\lambda=1.540598$ $\AA$ ), with a variable slit at $45 \mathrm{kV}$ and $40 \mathrm{~mA}$. The sample was scanned with a $2 \theta$ range of $5-90^{\circ}$. The International Centre for Diffraction Data (ICDD) database was used to reference the XRD patterns.

\subsubsection{Pre-Treatment of NEPs' Samples}

Due to the complex matrix of the NEPs, most samples (except for SAN1 and SAN2) could not be analysed directly (as purchased) and required some sample pre-treatment. Different ENMs isolation/extraction methods were used depending on the NEPs' matrix. Following ENMs isolation, the samples were prepared for characterisation using the techniques mentioned in Section 2.1.1. Since SAN1-2 required no sample pre-treatment, the ENMs in the NEPs suspension were directly examined.

\section{Sample Pre-Treatment for SUN1-5, LB1}

Pre-treatment of the NEPs' samples matrix was performed by following previously developed methods [1-3]. Briefly, $2 \mathrm{~g}$ of the product was extracted with $30 \mathrm{~mL}$ of methanol, hexane, chloroform, and 1\% Triton (pH12) (1:1:1:1 ratio). The suspension was vortexed for $5 \mathrm{~min}$, sonicated for $30 \mathrm{~min}$ at $25^{\circ} \mathrm{C}$, and centrifuged at $10,000 \mathrm{rpm}$ for $15 \mathrm{~min}$. The supernatants were discarded, and the extraction procedure was repeated twice. The solid pellet was air-dried, homogenised, and prepared for analysis with TEM-EDX and DLS. For NEPs where extraction methods yielded enough solid pellet mass, XRD was also performed.

\section{Sample Pre-Treatment for CA1-2}

A similar extraction method (SUN1-5, LB1) was adopted for CA1-2; the use of organic solvents was eliminated in this case. Briefly, $1 \mathrm{~g}$ of sample was introduced in $25 \mathrm{~mL}$ of Milli$\mathrm{Q}$ water and vortexed to homogeneity. The suspension was sonicated in a water bath for $30 \mathrm{~min}$ at $25^{\circ} \mathrm{C}$ and finally centrifuged at $10,000 \mathrm{rpm}$ for $30 \mathrm{~min}$. The organic component of the sample was removed, and the aqueous phase was concentrated by further centrifuging for $30 \mathrm{~min}$ at 10,000 rpm, followed by TEM-EDX and DLS analysis.

\section{Sample Pre-Treatment for CM1}

Two sample pre-treatment methods were performed for the isolation of ENMs from CM1. In the first sample pre-treatment phase, ENMs were isolated from the CM1 matrix using a method previously described (for SUN1-5, LB1). In the second method, a modified method of Bairi et al. [4] for Soxhlet extraction was used. Briefly, $2 \mathrm{~g}$ of the sample in a glass fibre thimble (Whatman, Merck, South Africa) was capped with a glass-wool plug that was previously baked at $400{ }^{\circ} \mathrm{C}$. The glass fibre thimble was transferred into the Soxhlet extractor. The $250 \mathrm{~mL}$ round-bottom flask was filled with $180 \mathrm{~mL}$ of hexane: dichloromethane (1:1) and four boiling chips were added; then, the flask was placed in a heating mantle to initiate the extraction process. The extraction process lasted for $5 \mathrm{~h}$. The 
organics were extracted into the solvent, while the particulates remained in the thimble. The thimble was air-dried, and the solid material was collected, homogenised, and prepared for TEM-EDX, DLS, and XRD analysis.

Sample Pre-Treatment for SAN3, and SK1

SAN3 and SK1 were subjected to two sample pre-treatment methods. For SAN3, the first pre-treatment method was similar to SUN1-5, LB1. In the second pre-treatment method, the ENMs were not isolated from the product matrix; rather, the sample as purchased was transferred into a crucible, frozen at $-80{ }^{\circ} \mathrm{C}$ for $24 \mathrm{~h}$, and dehydrated using a VirTis ${ }^{\circledR}$ Wizard 2.0 freeze dryer (SP Scientific, Johannesburg, South Africa). Afterwards, the dried sample was homogenised and prepared for analysis.

In the case of SK1, the fabric sample was cut into small pieces and prepared for SEM-EDX analysis in the first pre-treatment method. While in the second method, the modified protocol of Benn and Westerhoff [5] was used. Briefly, the cut pieces were ashed at $550{ }^{\circ} \mathrm{C}$ to reduce the bulkiness of the materials. The textile ashes were prepared for analysis. For SEM-EDX analysis, the ashes were directly prepared as highlighted in Section 2.1.1, while for TEM-EDX and DLS, the ashes were firstly dispersed in Milli-Q water and sonicated for $5 \mathrm{~min}$ before analysis.

\subsubsection{Elemental Quantification of NEPs}

The digestion of the samples followed a modified MARS 6 Method Note Compendium [6]. Briefly, $350 \mathrm{mg}$ (SUN1-5, LB1, CA1-2, CM1), $200 \mathrm{mg}$ (SK1), and $1 \mathrm{~mL}$ (SAN1-2) of the samples were transferred into the digestion vessels, and $5 \mathrm{~mL}$ of $\mathrm{HNO}_{3}$ was added (70\%, Sigma Aldrich, Johannesburg, South Africa), which was followed by swirling of the vessel and left open for approximately $10 \mathrm{~min}$. After $10 \mathrm{~min}, 2 \mathrm{~mL}$ of $\mathrm{H}_{2} \mathrm{O}_{2}$ (37\%, Sigma Aldrich, Johannesburg, South Africa); $\mathrm{H}_{2} \mathrm{O}_{2}$ was replaced with $1 \mathrm{~mL}$ of $\mathrm{HF}$ (49\%, Merck, Johannesburg, South Africa) in samples where Ti was present. The microwave digestion program followed the cosmetics and textiles heating program highlighted in the MARS 6 Method Note Compendium [6] for (SUN1-5, LB1, CA1-2, CM1, SAN1-2) and (SK1), respectively. In cases where the digestion was incomplete, the heating cycle was repeated until the sample was fully solubilised. After sample digestion, HF complexation was performed under conditions stipulated in the CEM Method Note Compendium [6].

A wet digestion method, under low temperature and atmospheric pressure, was used to promote complete digestion of PA1-5 [7]. Briefly, $350 \mathrm{mg}$ of a well-homogenised sample was weighed into a vessel, and $1 \mathrm{~mL}$ of $\mathrm{HNO}_{3}$ was added. The mixture was heated at $40{ }^{\circ} \mathrm{C}$ for $20 \mathrm{~min}$. After cooling, $5 \mathrm{~mL}$ of $\mathrm{HCl}$ (37\%, Merck, South Africa) and $1 \mathrm{~mL}$ of HF were added followed by $120^{\circ} \mathrm{C}$ heating of the mixture until the sample was fully solubilised (taking approximately $3-4 \mathrm{~h}$ ). Then, the vessels were transferred to a microwave to perform HF complexation using the conditions stipulated in the MARS 6 Method Note Compendium [6]. All NEPs' digests were filtered using $0.45 \mu \mathrm{m}$ (Merck, Johannesburg, South Africa) and prepared for inductively coupled plasma mass spectrometry analysis (ICP-MS, Icap Q, Thermo Fisher Scientific, Waltham, MA, USA), monitoring ${ }^{66} \mathrm{Zn},{ }^{48} \mathrm{Ti}$, ${ }^{107} \mathrm{Ag},{ }^{28} \mathrm{Si},{ }^{27} \mathrm{Al}$, and ${ }^{45} \mathrm{Sc}$ (internal standard). The efficiency of all the digestion methods was examined by digesting the standards in bulk form ( $\mathrm{Zn}, \mathrm{Ti}$, and $\mathrm{Ag}$ from Anatech instruments (Johannesburg, South Africa), nTiO 2 (Tavo-commercial nanocomposite, Merck, Johannesburg, South Africa), nAg (bare and aminated, Nanocomposix, San Diego, CA, USA), nZnO (Z-cote, a commercial nanocomposite, BASF, Johannesburg, South Africa). All the samples and standards were digested and analysed in triplicate; appropriate sample dilutions were performed before ICP-MS analysis.

\subsubsection{Data Analysis}

Violin plots and statistical analysis were performed using GraphPad Prism 8 version 8.4.3 for Windows (GraphPad Software La Jolla, San Diego, CA, USA). XRD curves were plotted using Microcal ${ }^{\mathrm{TM}}$ origin $^{\mathrm{TM}}$ version 9.7 (Microcal Software, Inc., Northampton, MA, 
USA). The Student's t-test and one-way ANOVA with a Tukey's HSD post hoc test were applied to test statistical difference at $p$-value of $<0.05$.

\section{Results and Discussion}

\subsection{Characterisation of ENMs in NEPs}

The ENMs' sizes were averaged and reported as width $\times$ length, particle size distributions for all NEPs and are presented in Figure S1; the data represent measurements of particles visualised on different locations on the $\mathrm{Cu}$ grid. The minimum number of ENMs' particles measured was set at 50. For CM1 and SK1 (irregularly shaped $\mathrm{nTiO}_{2}$ and $\mathrm{nAg}$ particles), the number of particles measured was lower than 50 because of the low confidence in identifying and measuring the particles that were associated with NEPs matrix, or the ENMs were distorted. Such is a common analytical limitation experienced in characterising ENMs in complex samples [8].

\subsubsection{Sunscreens}

The sunscreens (SUN1-5) were observed to contain ENMs (Figure 1 and Figure S2). The SUN1 contained elongated $\mathrm{nTiO}_{2}$ particles with sizes of $14 \pm 5 \times 62 \pm 11 \mathrm{~nm}$ and angular $\mathrm{nZnO}$ particles with sizes of $35 \pm 5 \times 38 \pm 4 \mathrm{~nm}$. $\mathrm{nTiO}_{2}$ and $\mathrm{nZnO}$ particles were distinguished through elemental mapping, as depicted in Figure 2. SUN2 and SUN3 contained only angular shaped $\mathrm{nTiO}_{2}$ sized $28 \pm 4 \times 32 \pm 5 \mathrm{~nm}$ and $20 \pm 2 \times 27 \pm 4 \mathrm{~nm}$ respectively; the two SPF50 sunscreens were of the same brand. In SUN4, elongated and angular $\mathrm{nTiO}_{2}$ were of sizes $7 \pm 2 \times 48 \pm 11 \mathrm{~nm}$ and $14 \pm 4 \times 17 \pm 1 \mathrm{~nm}$, respectively, and they were highly agglomerated compared to SUN1-3. In SUN5 (a suspect NEP), there were elongated $\mathrm{nTiO}_{2}$ sized at $9 \pm 2 \times 72 \pm 9 \mathrm{~nm}$, while $\mathrm{ZnO}$ particles were larger (129-151 × 254-316 nm) (Figure 1E) and outside the conventional 1-100 nm nano definition; however, it is possible they too had particulates in the nano size.

In all the sunscreens, the ENMs were observed to be still associated with coating agents evident from the EDX spectra in Figure S2. Silicon ( $\mathrm{Si}$ ) (from $\mathrm{SiO}_{2}$-based coatings) was observed in SUN2-3 and SUN5. Aluminium (Al; from Al-based coatings) was detected in SUN1, whereas both Si and Al coating were detected in SUN4. The ENMs incorporated in NEPs (sunscreens included) are commonly coated with layers of either $\mathrm{Al}_{2} \mathrm{O}_{3}, \mathrm{Al}(\mathrm{OH})_{3}$, and $\mathrm{Al}_{2} \mathrm{O}_{3}+\mathrm{SiO}_{2}$; these are intended to reduce the photo-reactivity and oxidative stress potential of the ENMs [9-12]. While the extraction methods may have altered the surface coating agents and agglomeration state, changes in the shape and particle size were not expected. A comparative study of cryo-TEM and TEM observed that only dis-agglomeration occurred between as-purchased and extracted samples [1]. Generally, the ENMs' size, shape, and elemental composition determined herein were comparable to previous studies $[1,3,4,13-18]$. 

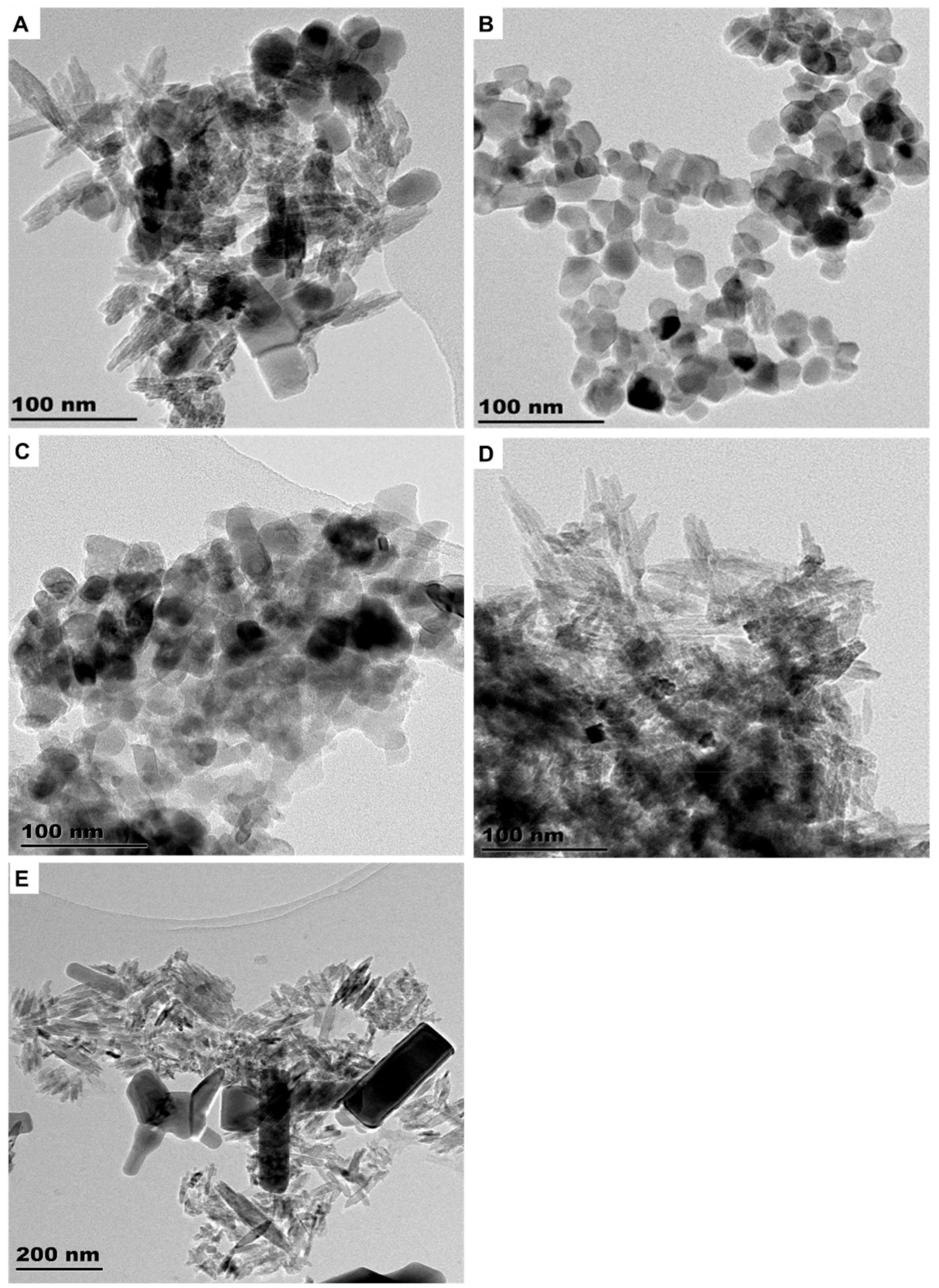

Figure 1. TEM images of engineered nanomaterials (ENMs) found in SUN1 (A), SUN2 (B), SUN3 (C), SUN4 (D), and SUN5 (E).

The ENMs in all the sunscreens were negatively charged (Table S1). The zeta potential of the ENMs ranged between -19 and $-52 \mathrm{mV}$, and since most ENMs were still associated with the ENMs coating agents, it was assumed that their surface charge was not considerably affected by the extraction procedures.

The results of crystal phase determination with XRD are depicted in Figure 3. The phases of $\mathrm{nTiO}_{2}$ and $\mathrm{nZnO}$ in SUN1 and SUN5 were rutile (ICDD ref code, 01-075-1755) and zincite (ref code, 00-036-1451), respectively. The prominent peaks for $\mathrm{TiO}_{2}$ were at $2 \theta$ of 27.4, 36.0, 41.2, and 54.3 and respectively corresponding to the (110), (101), (111), and (211) lattice planes. For $\mathrm{nZnO}$, the peaks were at $2 \theta=31.7,34.4,36.247 .5$, and 56.6, respectively corresponding to (110), (200), (101), (102), and (110). SUN2 contained anatase $\mathrm{nTiO}_{2}$ (ICDD ref code, 00-021-1272), with lattice planes of (101) and a corresponding peak at 25.3. SUN3 contained rutile $\mathrm{nTiO}_{2}$ (ICDD ref code, 01-078-1508); the prominent peak and 
the corresponding lattice planes were similar to the $\mathrm{nTiO}_{2}$ patterns observed in SUN1 and SUN5. In the case of SUN4, a mixture of rutile (ICDD ref code 01-078-1508) and anatase (ICDD ref code, 00-021-1272) was obtained. The prominent peaks and lattice plane were similar to the respective phases previously reported for the other sunscreens (SUN2 for anatase profile and SUN1 for rutile profile).
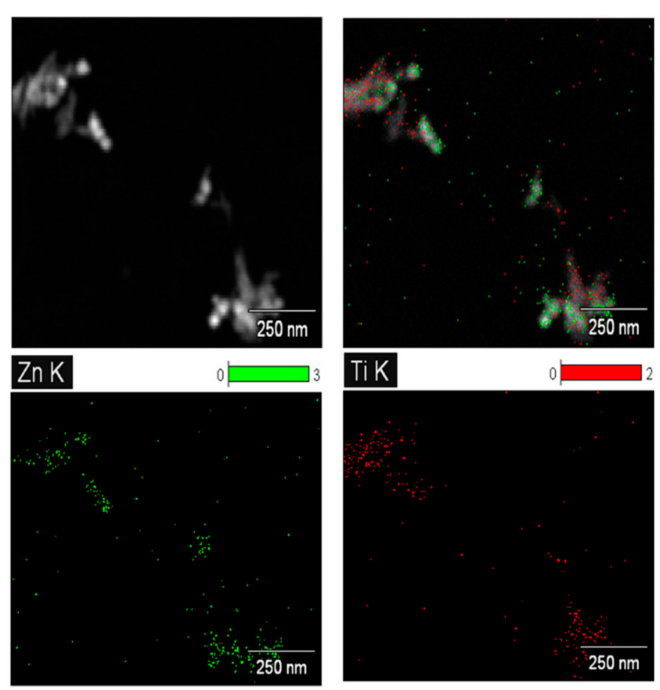

A
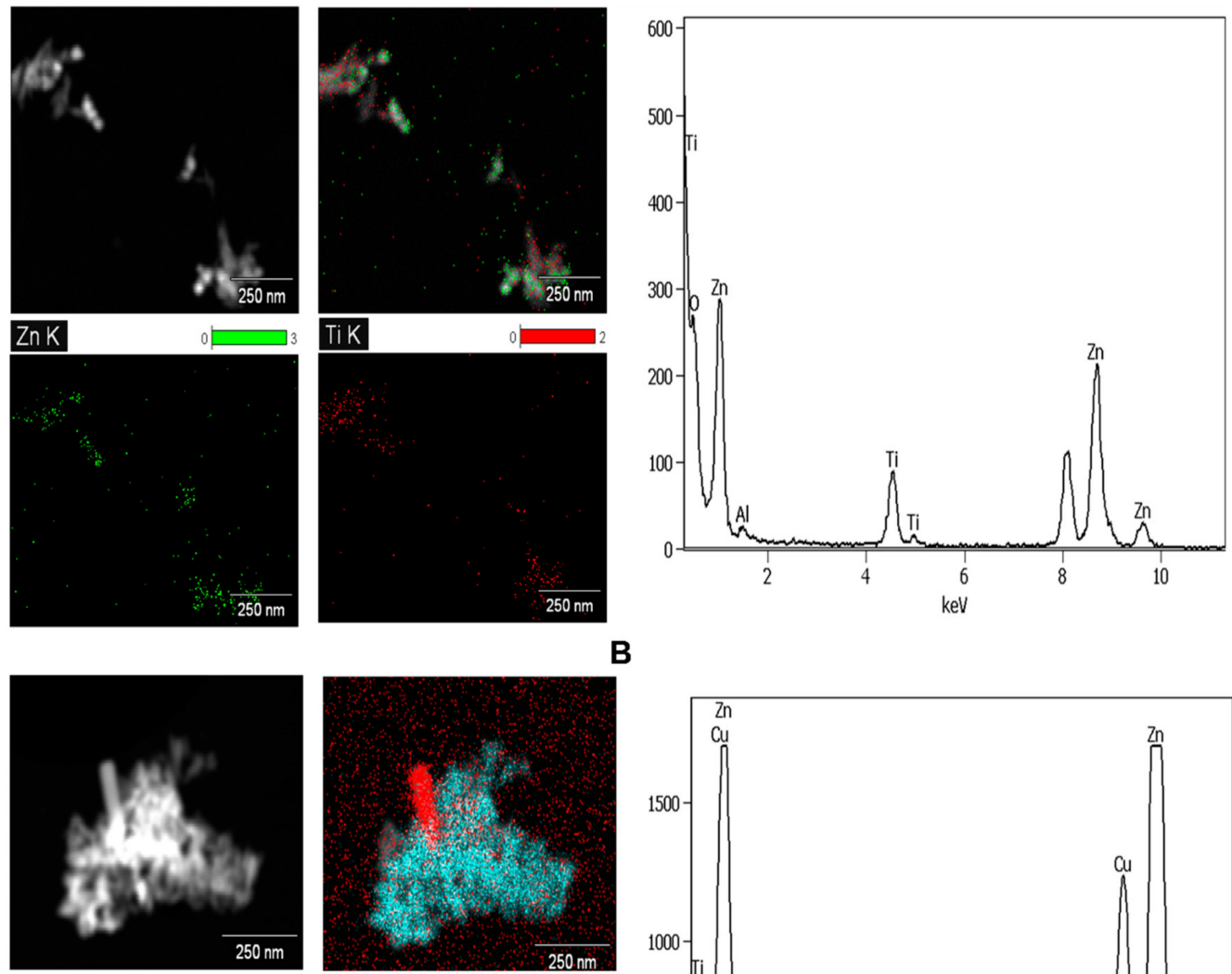

B
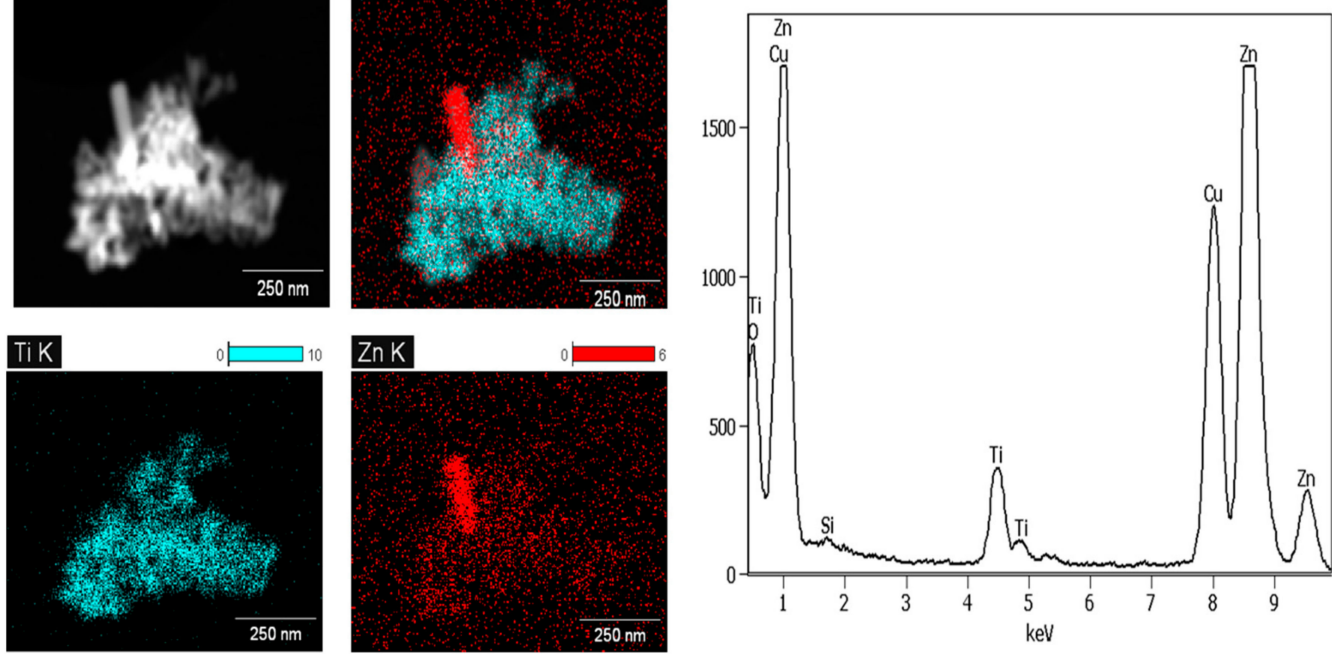

Figure 2. The energy-dispersive $\mathrm{X}$-ray (EDX) elemental mapping for the identification of $\mathrm{nTiO}_{2}$ and nZnO detected in SUN1 (A) and SUN5 (B). 

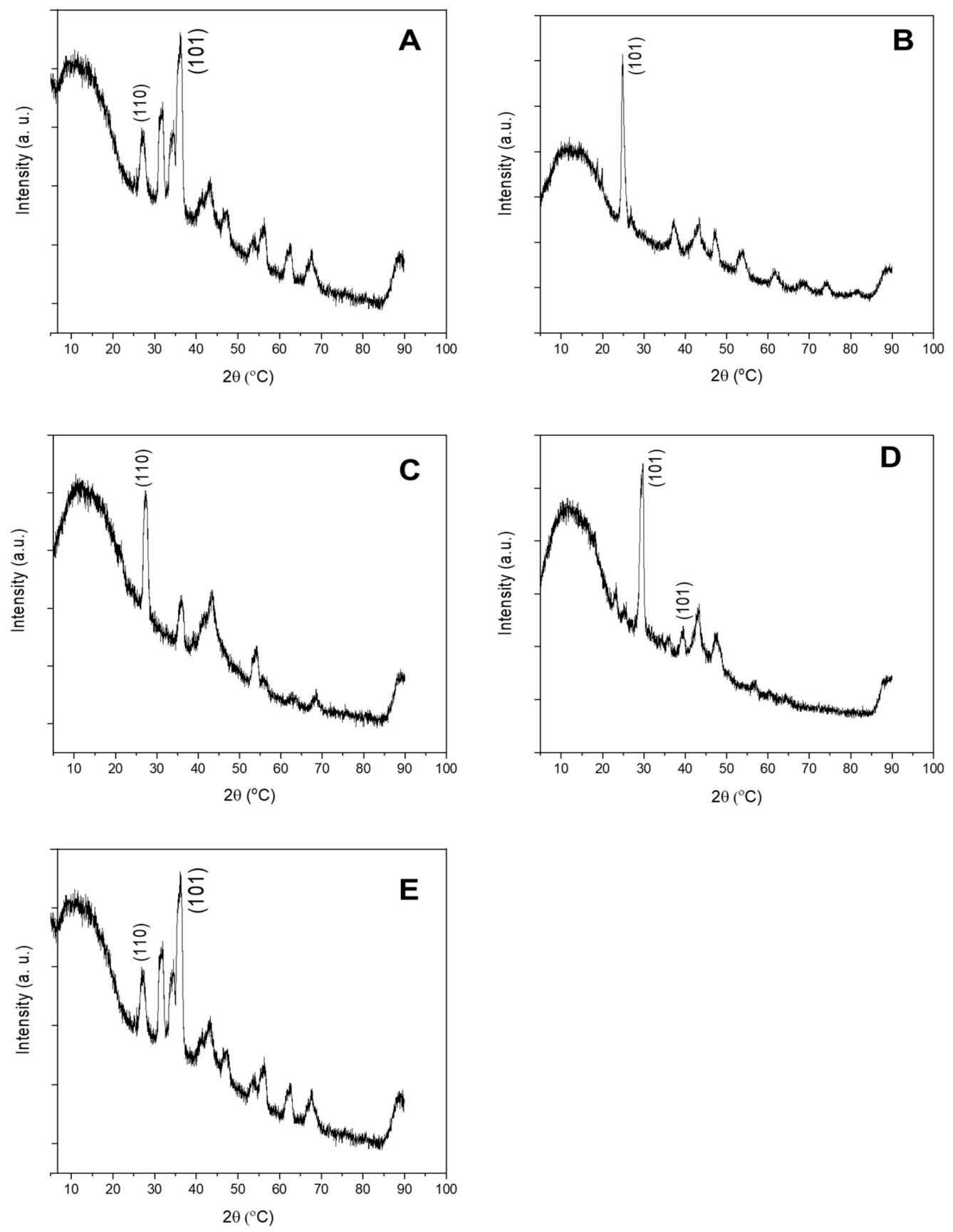

Figure 3. The XRD patterns of SUN1 (A), SUN2 (B), SUN3 (C), SUN4 (D), and SUN5 (E).

The incorporation of rutile $[4,13,19]$, anatase $[4,19,20]$, brookite [21], or a mixture of rutile and anatase [21] in products has been reported previously. Rutile $\mathrm{nTiO}_{2}$ is preferred because of its high UV absorption gap (wavelength of $407 \mathrm{vs.} 387 \mathrm{~nm}$ for anatase) [22] and because of the low photo-reactivity compared to highly reactive anatase that can produce hydroxyl radicals under ultraviolet treatment [23]. A mixture of $\mathrm{TiO}_{2}$ forms, as in the case of sample SUN4, appears to be uncommon because only a single case has been reported [21]. So far, the examination of the $\mathrm{ZnO}$ crystal structure in sunscreens has been limited to a few reports [4,21]; both studies identified the wurtzite phase of $\mathrm{ZnO}$.

\subsubsection{Personal Care Products}

Most of the personal care subcategory products were found to be nano-enhanced (Figures 4-6), except for SAN3, where no ENMs were detected. As shown in Figure 4, 
LB1 contained elongated $\mathrm{nTiO}_{2}(6.5 \pm 2 \times 52.2 \pm 14 \mathrm{~nm})$ and angular $\mathrm{nZnO}(33 \pm 6 \times$ $37 \pm 7 \mathrm{~nm}$ ). XRD analysis of LB1 could not be performed due to the low sample mass obtained after the extraction procedure; this is another practical limitation concerning the examination of ENMs in NEPs, especially toxicity effects assessments [3,24]. Since SUN1 and LB1 were from the same manufacturer and found to contain the same type and comparable size of ENMs; it is most likely that the $\mathrm{nTiO}_{2}$ and $\mathrm{nZnO}$ used in both products were similar. As in SUN1, the ENMs in LB1 were negatively charged $(-19 \mathrm{mV})$.
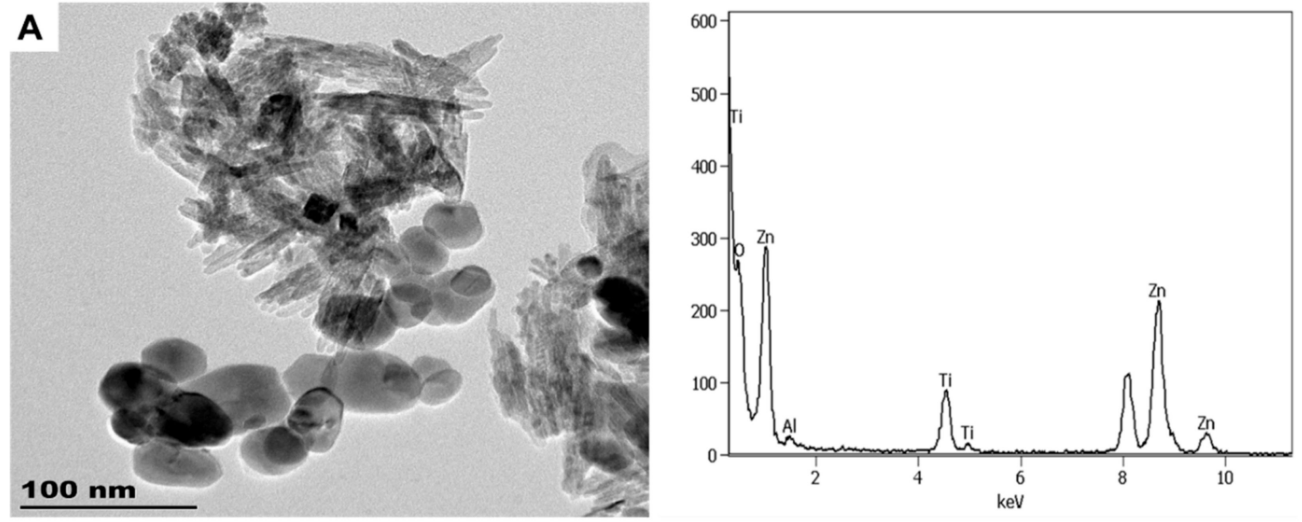

\section{B}
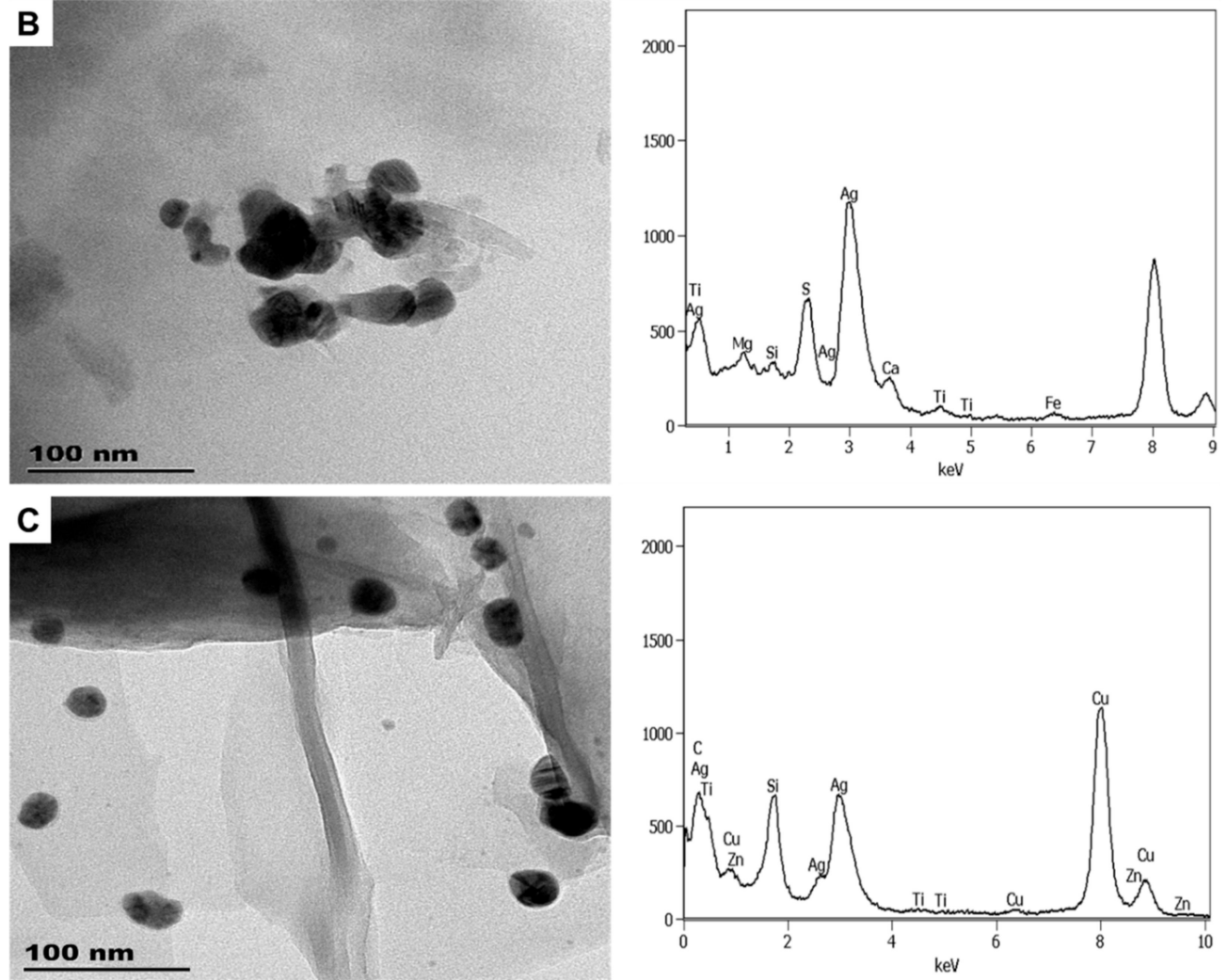

Figure 4. The images and spectra of TEM-EDX analysis of LB1 (A), CA1 (B), and CA2 (C). 

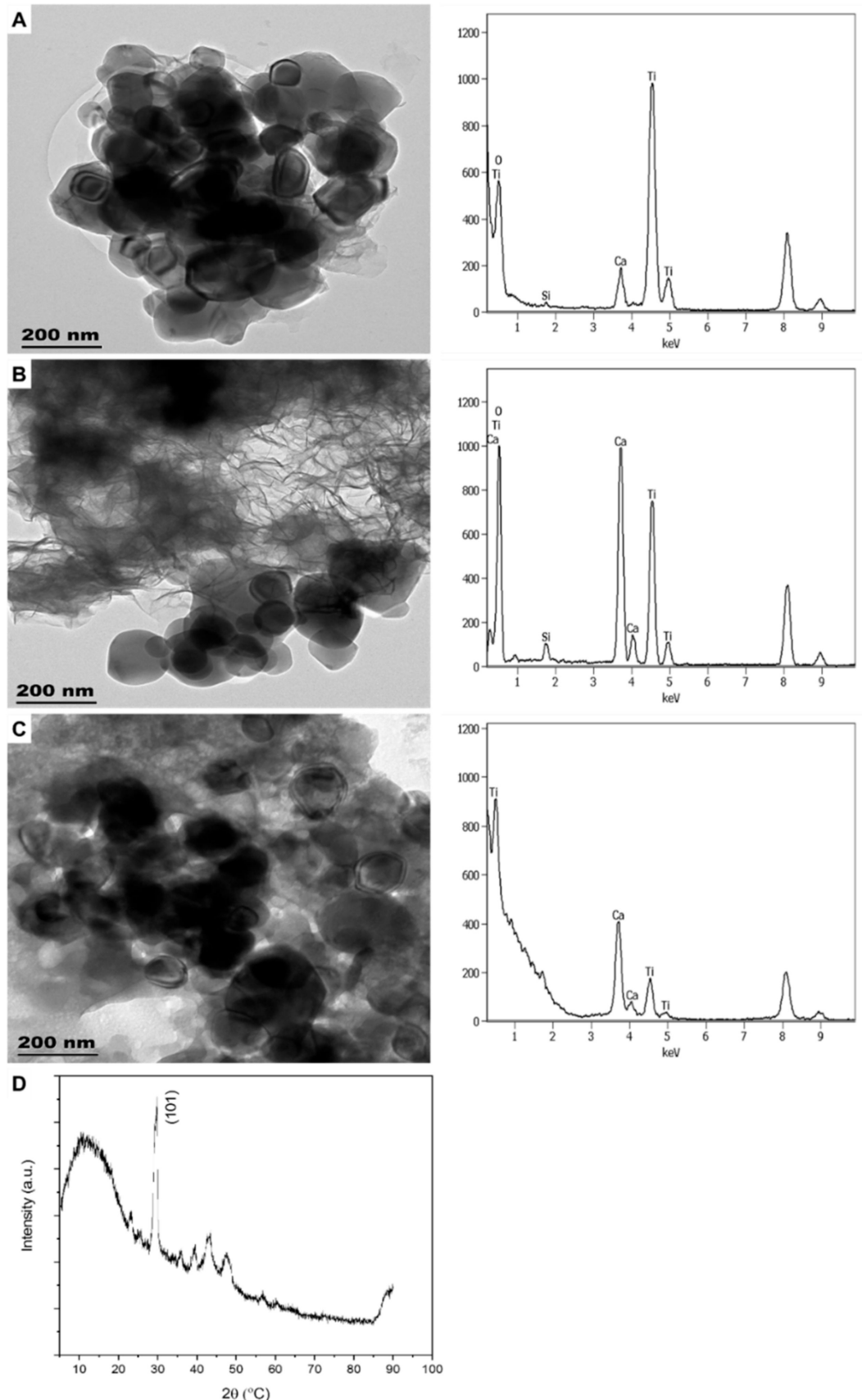

Figure 5. Transmission electron microscopy coupled with energy-dispersive X-ray (TEM-EDX) analysis of ENMs obtained from CM1 after (A) sequential ultrasonication, (B) Soxhlet extraction, (C) diluted nano-enabled products (NEPs), and (D) corresponding X-ray powder diffraction (XRD) spectra.

The "suspect" products, CA1 and CA2, were found to contain ENMs (Figure 4); thus, they were confirmed as NEPs. CA1 had elongated $\mathrm{nTiO}_{2}$ sized $8 \pm 2 \times 53 \pm 18 \mathrm{~nm}$ and near-spherical $\mathrm{nAg}$ sized $27.5 \pm 7 \mathrm{~nm}$. CA2 had near-spherical $\mathrm{nAg}$ particles with a size range of $21.7 \pm 6 \mathrm{~nm}$. Although CA1 and CA2 were from different manufacturers, their $\mathrm{nAg}$ sizes were relatively similar. The zeta potentials of the ENMs in CA1 and CA2 were closely related at -34 and $-36 \mathrm{mV}$, respectively. Similar to LB1, XRD analysis for CA1-2 could not be undertaken because of the low sample mass obtained after the extraction procedure. 

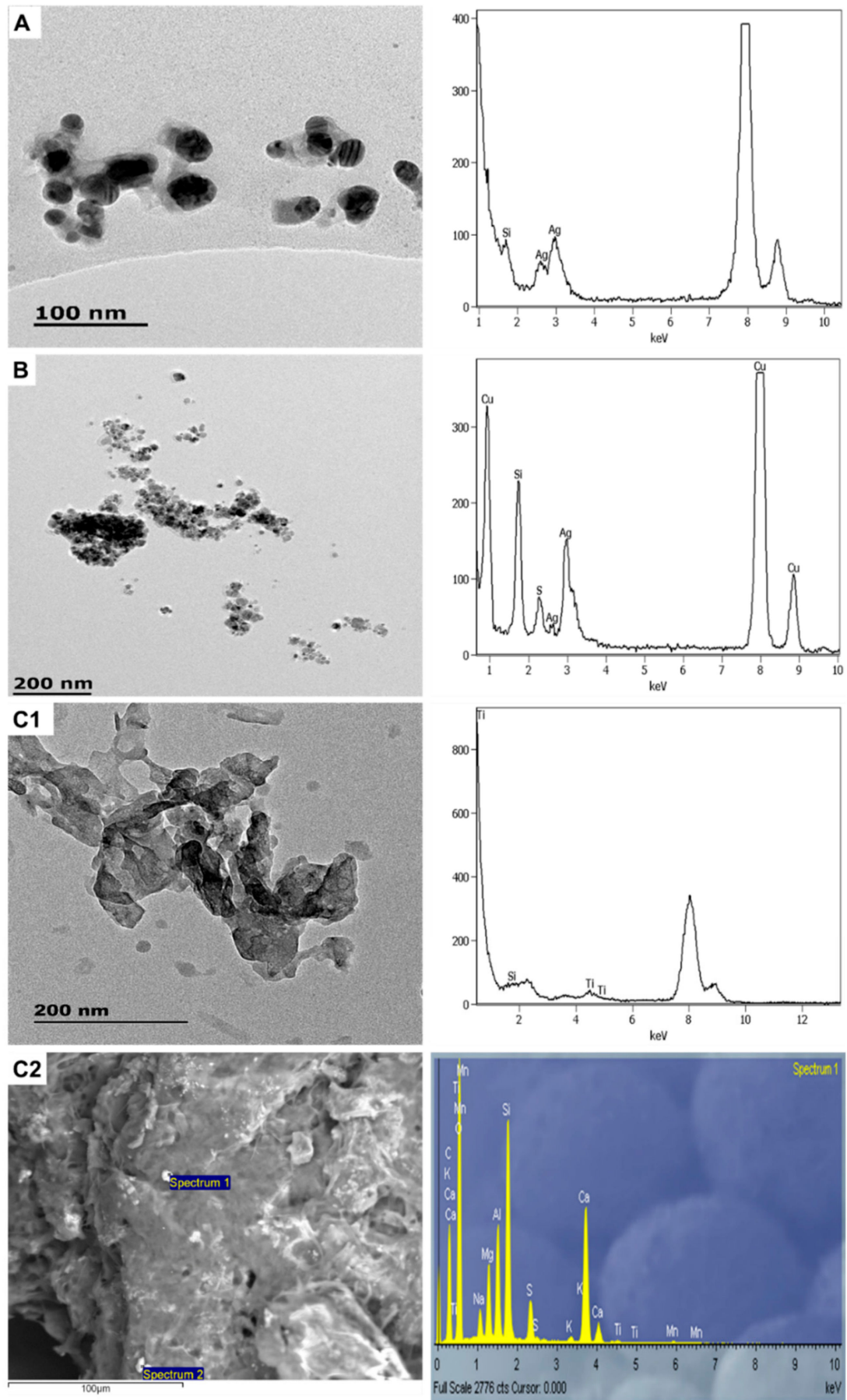

Figure 6. The TEM- and SEM-EDX characterisation of ENMs incorporated in SAN1 (A), SAN2 (B), and SAN3 $(\mathbf{C} 1, \mathrm{C} 2)$.

According to the manufacturer, $\mathrm{CM} 1$ contained $\mathrm{nSiO}_{2}$; however, only the bulk form was detected (Figure 5). Furthermore, even after employing different extraction procedures, $\mathrm{SiO}_{2}$ in the nano-form was not observed, but instead, $\mathrm{nTiO}_{2}$ was detected. The $\mathrm{nTiO}_{2}$ was angular in shape and had a size range of 32-151× 62-168 nm; sizes obtained from different sample pre-treatments were comparable, indicating that none of the methods employed distorted the particle size. The $\mathrm{nTiO}_{2}$ was negatively charged $(-18 \mathrm{mV})$ and of anatase form (ICDD ref code, 00-021-1272); the XRD patterns were similar to those of SUN2.

The sanitisers (SAN1-2) contained near-spherical nAg (Figure 6). SAN1 contained two distinct particle sizes of $22 \pm 7$ and $37 \pm 4 \mathrm{~nm}$; the larger counterparts appeared to be due to an agglomeration effect. The $\mathrm{nAg}$ contained in SAN2 was $20 \pm 4 \mathrm{~nm}$ in size. The ENMs' 
surface charge in SAN1 and SAN2 was comparable at $-22 \mathrm{mV}$ and $-23 \mathrm{mV}$. XRD analysis was not undertaken on SAN1-2 as they were in liquid form. SAN1 and SAN2 were both not labelled to be nano-enhanced, but analysis undertaken herein confirmed them to be NEPs. In SAN3, no ENMs were found even after exploring different sample preparation techniques (Figure 6C1,C2); thus, no further characterisation was undertaken.

\subsubsection{Socks}

For clothing NEPs, SK1 contained $\mathrm{nAg}$ and $\mathrm{nTiO}_{2}$, where the manufacturer had only declared the incorporation of $\mathrm{nAgCl}$. The $\mathrm{nAg}$ was near-spherical and irregular, whereas $\mathrm{nTiO}_{2}$ was angular $(32-203 \times 48-135 \mathrm{~nm})$. The near-spherical $\mathrm{nAg}$ particles were sized $18 \pm 5 \mathrm{~nm}$, while irregularly shaped counterparts consisted of two size sets of $36 \pm 9 \times 34 \pm 13 \mathrm{~nm}$ and $85 \pm 21 \times 65 \pm 33 \mathrm{~nm}$. Although ENMs' size and shape were established, in some cases, the ashing procedure altered the particle shape of $\mathrm{nAg}$ in/on the sock (Figure 7). The ENMs surface charge of ashed material was $-13 \mathrm{mV}$; it is most likely that the charge of the ENMs was affected by the ashing procedure.
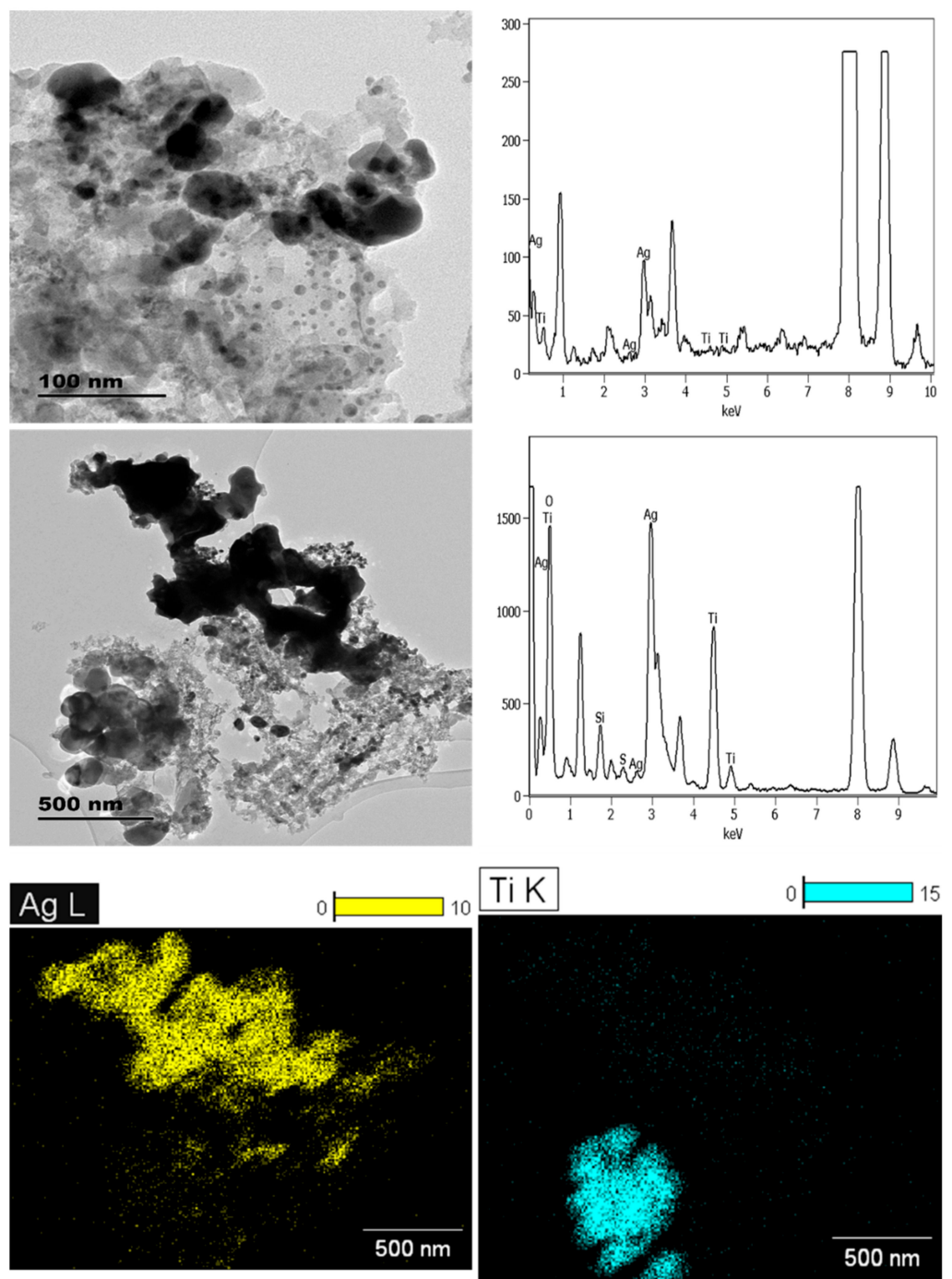

Figure 7. TEM-EDX analysis of ashed SK1 and elemental mapping showing the presence of nAg (yellow) and $\mathrm{nTiO}_{2}$ (blue).

The irregularly shaped nAg appeared to be ashing-induced agglomeration. Though ashing interfered with the ENMs shape in SK1, the procedure was deemed necessary to remove the bulkiness of the sock fabric material and thus revealing the ENMs. EDX elemental 
mapping distinguished the $\mathrm{nTiO}_{2}$ from $\mathrm{nAg}$ in SK1 (Figure 7). To date, the characterisation of ENMs in fabrics has mainly been on laboratory-developed products [25-29], as compared to commercial textiles in which 100-500 nm nearly spherical $\mathrm{nAg}$ and irregular shaped $(<100 \mathrm{~nm})$ have been reported $[5,30]$.

SEM-EDX characterisation data for SK1 was generally inconclusive (Figure 8A,B). The lack of detection of ENMs by SEM-EDX (a surface characterisation technique) suggested that the ENMs were inside the NEPs matrix and not surface coated. This possibility was further supported by TEM-EDX analysis (Figure 8C), whereby the ENMs (especially nAg) were seen to be deposited in a straight line inside the textile fibre. The location of ENMs in NEPs plays a significant role in the release potential of ENMs; for example, ENMs that are surface coated exhibit high release potential as compared to ENMs suspended in solid/matrix [19]. Similar to other personal care products (excluding CM1), the sample mass obtained after SK1 ashing was not sufficient to perform XRD analysis.
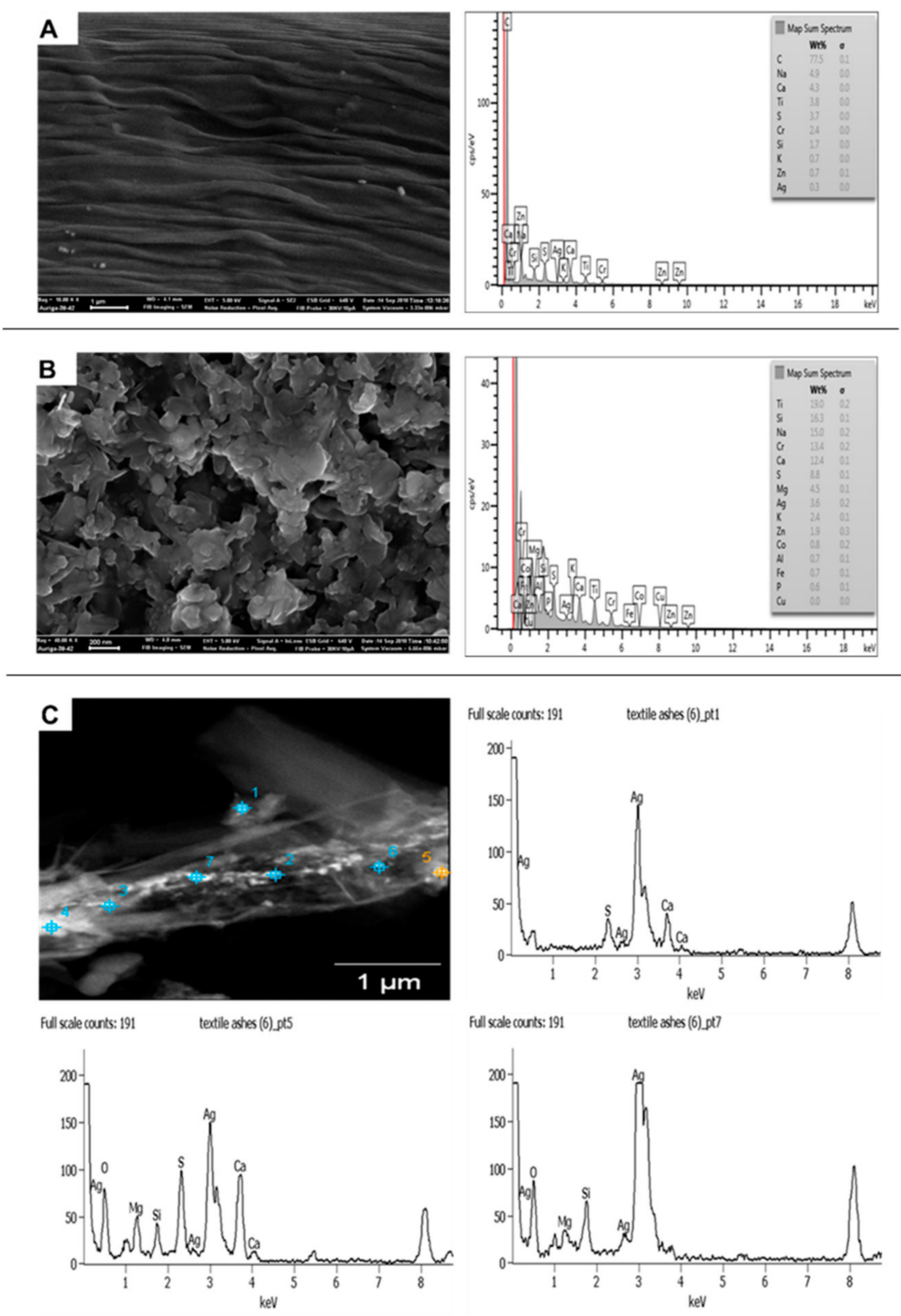

Figure 8. Scanning electron microscopy coupled to energy-dispersive X-ray (SEM-EDX) images of non-ashed (A) and ashed (B) SK1 and TEM-EDX of SK1 showing nAg in a straight line within the fibre $(\mathbf{C})$. 


\subsubsection{Paints}

Angular particles of $\mathrm{nTiO}_{2}$ with varying sizes were detected in all paint "suspects" (PA1-5) (Figure 9 and Figure S3). The $\mathrm{nTiO}_{2}$ were measured to be $200 \pm 56 \times 253 \pm$ $100 \mathrm{~nm}(\mathrm{PA} 1), 199 \pm 47 \times 251 \pm 84 \mathrm{~nm}(\mathrm{PA} 2), 197 \pm 49 \times 239 \pm 62 \mathrm{~nm}(\mathrm{PA} 3), 168 \pm$ $53 \times 239 \pm 60 \mathrm{~nm}$ (PA4), and $175 \pm 41 \times 178 \pm 48 \mathrm{~nm}$ (PA5). Fe-based ENMs with an elongated rod structure of $40 \pm 12 \times 297 \pm 139 \mathrm{~nm}$ size were also observed in PA1. Angular $\mathrm{nTiO}_{2}$ ranging $90-300 \mathrm{~nm}$ has previously been reported in paints [31,32]. The ENMs in paints were all negatively charged and ranged between -12 and $-20 \mathrm{mV}$ (Table S1). The $\mathrm{nTiO}_{2}$ incorporated in PA1-PA5 was all in the rutile phase (Figure 10), with ICDD ref codes 00-021-1276 (PA1), 01-076-0649 (PA2), 01-072-1148 (PA3, PA4), and 01-073-2224 (PA5). The prominent peaks and the corresponding lattice plane were observed at $2 \theta=27.4$ (110), 36.0 (101), and 54.3 (211). The use of anatase $\mathrm{nTiO}_{2}$ in paints has previously been reported [32].
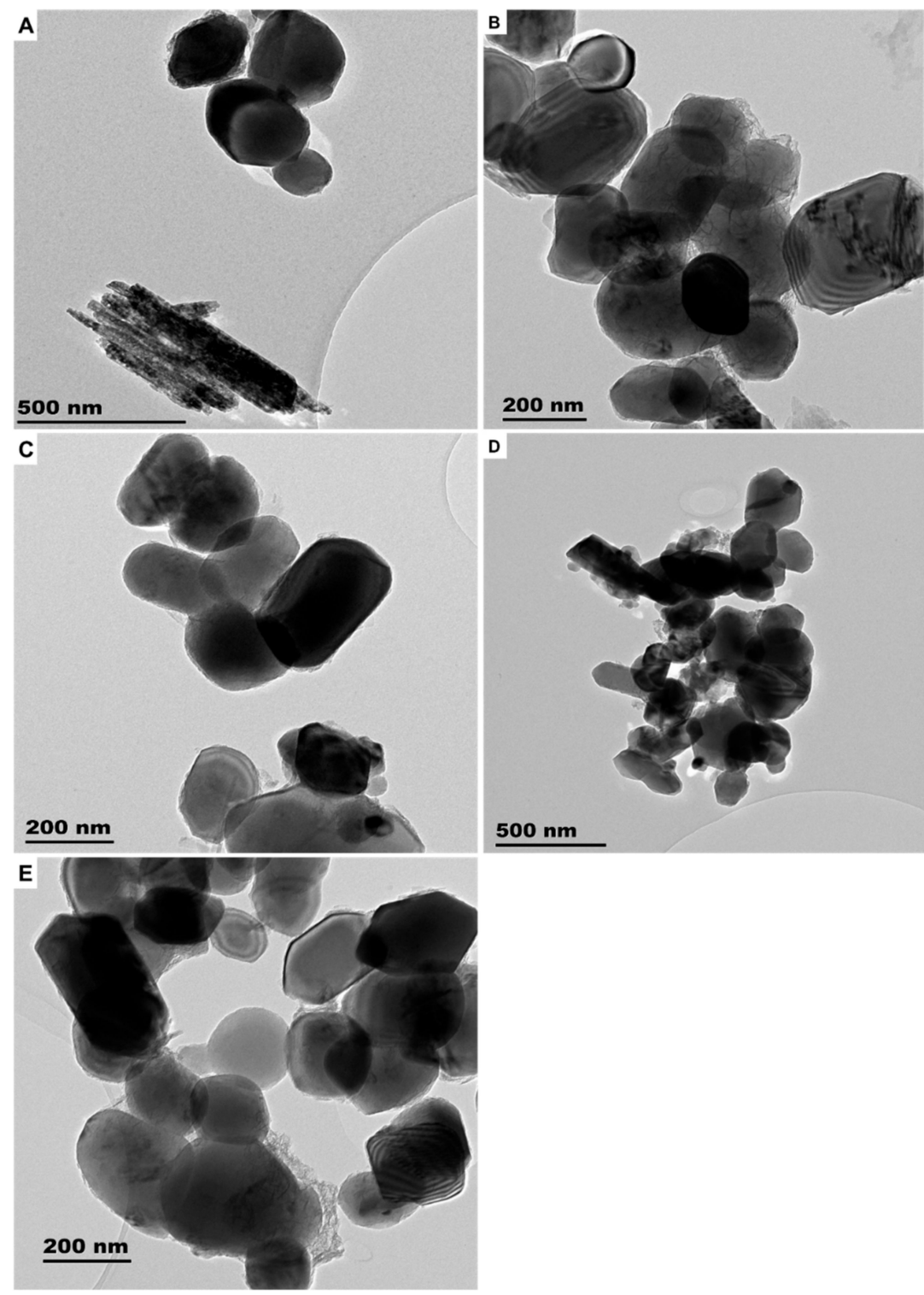

Figure 9. TEM images obtained from the analysis of PA1 (A), PA2 (B), PA3 (C), PA4 (D), and PA5 (E). 

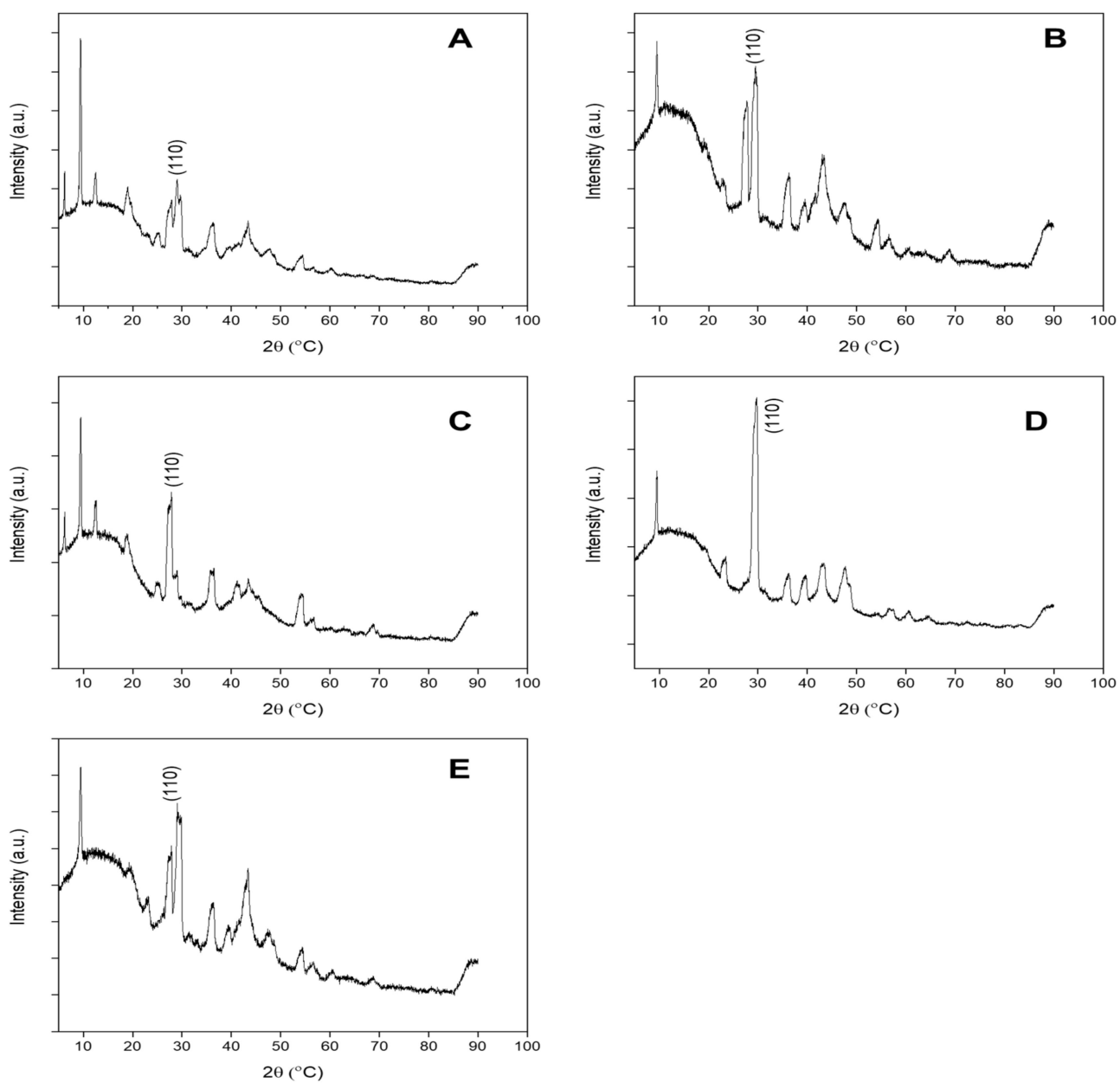

Figure 10. The XRD patterns of PA1 (A), PA2 (B), PA3 (C), PA4 (D), and PA5 (E).

\subsection{Elemental Quantification of ENMs in NEPS}

The total elemental concentrations of the labelled and suspect NEPs are reported in Table 2. The analysis techniques were satisfactory, as the recoveries of the standards highlighted in Section 2.1.3 were in the ranges of (75-107\%) Ti, (72-97\%) Ag, and (74$98 \%) \mathrm{Zn}$. The elements of ENMs that were not declared or suspected, but observed during sample characterisation, were also quantified and reported in Table 2. The ENMs quantities, irrespective of ENMs type in paints products, are seldomly reported. From the commercial paints incorporated with bulk $\mathrm{TiO}_{2}$, Ti concentrations ranged between 0.00044 and $2.8 \%$ $(w / w)[7,41]$.

The amounts determined in SUN1-5 were in agreement with a previously reported total Ti concentration of $0.34-13.1 \%(w / w)[1,19,33-35]$ and total $\mathrm{Zn}$ concentration of 2-20\% $(w / w)$ [14]. The amounts found in Ag-based personal care products SAN1-2 and CA1-2 were found to be lower than those declared by manufacturers; CA2 was an exception, where the determined concentration of $14 \mathrm{mg} / \mathrm{L}$ was closer to the $18 \mathrm{mg} / \mathrm{L}$ declared by the manufacturer. 
Table 2. The total elemental concentration of the ENMs found in NEPs.

\begin{tabular}{|c|c|c|c|}
\hline Sample & Target Analyte & $\begin{array}{c}\text { Claimed } \\
\text { Concentration (\%) }\end{array}$ & Concentration (\%) \\
\hline \multirow{2}{*}{ SUN1 } & $\mathrm{Zn}$ & not listed & $4.31 \pm 0.86^{b}$ \\
\hline & $\mathrm{Ti}$ & not listed & $1.72 \pm 0.41^{\mathrm{b}}$ \\
\hline SUN2 & $\mathrm{Ti}$ & not listed & $0.945 \pm 0.06^{b}$ \\
\hline SUN3 & $\mathrm{Ti}$ & not listed & $1.62 \pm 0.08^{b}$ \\
\hline SUN4 & $\mathrm{Ti}$ & not listed & $2.10 \pm 0.06^{b}$ \\
\hline \multirow{2}{*}{ SUN5 } & $\mathrm{Zn}$ & not listed & $6.84 \pm 0.56^{b}$ \\
\hline & $\mathrm{Ti}$ & not listed & $2.60 \pm 0.32^{b}$ \\
\hline \multirow{2}{*}{ LB1 } & $\mathrm{Zn}$ & not listed & $3.40 \pm 0.04^{b}$ \\
\hline & $\mathrm{Ti}$ & not listed & $1.41 \pm 0.35^{\mathrm{b}}$ \\
\hline \multirow{2}{*}{ CA1 } & $\mathrm{Ag}$ & $1.80 \times 10^{-3 \mathrm{a}}$ & $8.25 \times 10^{-4} \pm 3.54 \times 10^{-5 b}$ \\
\hline & $\mathrm{Ti}$ & not listed & $2.31 \times 10^{-4} \pm 8.8 \times 10^{-6 b}$ \\
\hline CA2 & $\mathrm{Ag}$ & $1.80 \times 10^{-3 \mathrm{a}}$ & $1.46 \times 10^{-3} \pm 1.7 \times 10^{-5 b}$ \\
\hline CM1 & $\mathrm{Ti}$ & Not listed & $0.949 \pm 0.04^{\mathrm{b}}$ \\
\hline SAN1 & $\mathrm{Ag}$ & $1.80 \times 10^{-3 \mathrm{a}}$ & $11.3 \times 10^{-3} \pm 3.18 \times 10^{-5 c}$ \\
\hline SAN2 & $\mathrm{Ag}$ & $1.80 \times 10^{-3 \mathrm{a}}$ & $8.13 \times 10^{-4} \pm 3.0 \times 10^{-5 c}$ \\
\hline PA1 & $\mathrm{Ti}$ & not listed & $2.09 \pm 0.24^{b}$ \\
\hline PA2 & $\mathrm{Ti}$ & not listed & $2.79 \pm 0.55^{b}$ \\
\hline PA3 & $\mathrm{Ti}$ & not listed & $2.76 \pm 0.43^{b}$ \\
\hline PA4 & $\mathrm{Ti}$ & not listed & $0.22 \pm 0.02^{b}$ \\
\hline PA5 & $\mathrm{Ti}$ & not listed & $1.67 \pm 0.23^{b}$ \\
\hline \multirow{2}{*}{ SK1 } & $\mathrm{Ag}$ & $2.00^{b}$ & $0.181 \pm 0.004^{b}$ \\
\hline & $\mathrm{Ti}$ & not listed & $1.31 \pm 0.07^{\mathrm{b}}$ \\
\hline
\end{tabular}

The difference between the determined and declared quantity is not uncommon; for example, Cascio et al. [36] and Wasukan et al. [37] found that in some products, the listed and determined amounts vary by as much as ten-fold, but in some products, the determined and declared quantities were relatively similar. Sometimes, there can be differences between product batches from the same manufacturer [38]. Although the amounts determined for nAg-based NEPs were commonly found to be lower than the declared, the amounts often agreed with those reported in the literature. For example, the quantity of total Ag in SK1 was comparable $(0.00015-0.29 \%(w / w))$ to previous studies investigating $\mathrm{nAg}$ in nanoenabled socks; the incorporation of $\mathrm{Ag}$ content ranging from 0.0001 to $>1 \%(w / w)$ has been considered normal in commercial textiles [30].

The quantification of Ti in commercial textile NEPs is rare; in the few available reports, the total Ti was reported to be at $0.00026-0.145 \%(w / w)$ [40]. Windler et al. [40] reported total $\mathrm{Ti}$ at $0.68-0.71 \%(w / w)$ in commercial textiles that were not nano labelled by the supplier company but were confirmed to be $\mathrm{nTiO}_{2}$. The same study further reported total Ti amounts in the range of $0.30-0.85 \%(w / w)$ in textile products that had no nano labelling. The ENMs quantities, irrespective of ENMs type in paints products, are seldomly reported. From the commercial paints incorporated with bulk $\mathrm{TiO}_{2}$, $\mathrm{Ti}$ concentrations ranged between 0.00044 and $2.8 \%(w / w)[7,41]$.

Thus far, the amount of ENMs added in various commercial NEPs has mostly been determined in the products as a whole using conventional spectrometric techniques such as inductively coupled plasma (ICP) coupled to different detectors (X) $[1,7,14,15,19,30$, $33,34,36,37,39,40,42,43]$. Conventional spectrometric techniques analysis requires prior sample pre-treatment such as acid digestion and an analysis method (elemental analysis) that quantifies both the bulk and nano particulates; thus, the accurate determination of ENMs amounts is not achieved. The quantification of ENMs added in NEPs specific to the particle are scarce. In rare cases, single-particle inductively coupled plasma mass spectrometry (spICP-MS) quantified the particle concentration of $\mathrm{nTiO}_{2}$ at $1.9 \times 10^{2}-4.8 \times$ $10^{5}$ parts $/ \mathrm{mL}[15,42,43]$ and $\mathrm{nZnO}$ at $1.4 \times 10^{3}-1.0 \times 10^{4}$ particle $/ \mathrm{mL}[43]$ in sunscreens 
and $1.0 \times 10^{4}-3.9 \times 10^{5}$ particles $/ \mathrm{mL}$ in personal care products (i.e., shampoos, facial cream, toothpaste, lip balm, and day cream) [42]. The determination of particle concentration of ENMs added in NEPs is emerging [39]; the growing application of spICP-MS and reporting of ENMs particle concentration in complex environmental media has been reported [44,45].

Overall, the amounts of ENMs determined using spICP-MS (particle/volume) and conventional spectroscopic techniques (mass/volume) differ; the difference is not consistent, and different studies reported an overestimation or underestimation, and no difference in the amounts of ENMs $[15,39,43,44,46]$. The difference is due to various factors, one being that the conventional spectroscopic techniques determine the total concentration of the target analyte (bulk, ENMs, and ions), while spICP-MS only determines the ENMs particle concentration [47,48]. Sample preparation, dilution, and evaporation in spICP-MS and acid digestion in ICP-X techniques also possibly contribute toward the different amounts determined by the two techniques [39].

While both techniques provide the amount of ENMs added in NEPs, quantification using such methods is associated with drawbacks. For example, the sample preparation time is longer with conventional spectroscopic techniques compared to spICP-MS, and the concentration specific to the ENMs is lost. spICP-MS techniques suffer from isobaric interferences; correcting the isobaric interferences often leads to decreased sensitivity, thus increasing the size detection limit [39]. Furthermore, it is challenging to obtain consistent/reproducible measurements of size, size distribution, and the number of particle concentration using spICP-MS [49]. Nonetheless, spICP-MS is a promising technique that can rapidly provide comprehensive physico-chemical properties data of ENMs (i.e., particle concentration, size distribution, apparent core density, and state of aggregation) $[47,50,51]$.

\section{Concluding Remarks}

In pursuit of advancing knowledge with regard to the environmental implications of nanotechnology, it is essential that the estimation of ENMs exposure potential be highly relevant to the ENMs lifecycle. The current study sought to expand knowledge about the physico-chemical characteristics of ENMs in NEPs as potential sources of nanopollution; the study was exclusive to a sample of NEPs that exhibit high likelihood to nanopollute water resources.

The complementary analytical methods applied in this study were largely successful in establishing the physico-chemical properties of ENMs in NEPs. Seventeen (94\%) products examined herein contained ENMs and were thus confirmed to be NEPs. The "suspects" products, namely, SUN5, CA1-2, SAN1-2, and PA1-5 were determined to contain ENMs and were thus confirmed as NEPs. Due to the limited regulatory requirement for manufacturers to nano-declare, consequentially, the modelling estimations of environmental exposure solely based on nano-declared products may be underestimated, thus resulting in lower risk estimation. It is on such basis that efforts to better estimate the extent of nanopollution can be enhanced by introducing mandatory declaration of NEPs by manufacturers (reliable country NEPs inventory) solely to establish the baseline of nanopollution potential.

Generally, the ENMs in NEPs widely differed (in type, size, shape, and composition) but were all negatively charged. Of the $17 \mathrm{NEPs}, 9(52 \%), 3(18 \%), 3(18 \%)$, and $2(12 \%)$ were incorporated with $\mathrm{nTiO}_{2}, \mathrm{nAg}$, binary $\mathrm{nZnO}+\mathrm{nTiO}_{2}$, and $\mathrm{nTiO}_{2}+\mathrm{nAg}$, respectively. Hence, ENMs' environmental emissions (i.e., nanopollution) from NEPs can be generally expected to be in that order, provided that market penetration and product life cycle dynamics are not factored.

The characterisation of liquid suspended ENMs (SAN1-2) was relatively easier compared to those in semi-liquid NEPs (SUN1-5, CA1-2, CM1, and PA1-5) and surface-bound (SK1); therefore, more efforts are needed to develop reliable and even standardised characterisation methods especially for the former. The findings further strengthened the applicability of the "ENMs fixation parameter" for low tier estimation of potential for nanopollution. 
Overall, the study demonstrated that some existing conventional techniques are capable to a large extent of characterising ENMs in NEPs, as long as the sample techniques effectively isolate the ENMs from the other product components. Inappropriate and ineffective techniques for ENMs isolation can introduce artefacts and cause misinterpretation of the results. We raise that the determination of the concentration of the ENMs solely based on the total elemental concentration remains a global weakness in studies of this nature, arising from the inadequacy of current techniques and limited accessibility/awareness of some of the latest options. On that basis, we recommend heightened efforts to test and refine some of the relatively new techniques, for instance, the spICP-MS and Nanoparticle Tracking Analysis for more accurate characterisation of the concentration parameter, coupled with effective techniques for ENMs isolation.

Supplementary Materials: The following are available online, Figure S1: A Violin plot showing the overall particle size distribution of ENMs characterised in NEPs. Figure S2: EDX of ENMs found in SUN1 (A), SUN2 (B), SUN3 (C), SUN4 (D), and SUN5 (E). Figure S3: EDX spectra's obtained from the analysis of PA1 (A), PA2 (B), PA3 (C), PA4 (D), and PA5 (E)., Table S1: Zeta potential of the ENMs (extracts) incorporated in NEPs.

Author Contributions: Conceptualisation, M.T., and R.F.L.; Methodology, R.F.L., and M.T.; Software, R.F.L.; Validation, M.T., Y.T., and A.M.; Formal Analysis, R.F.L.; Investigation, R.F.L.; Resources, M.T., and Y.T.; Data Curation, R.F.L.; Writing-Original Draft Preparation, R.F.L.; Writing-Review and Editing, R.F.L., M.T., Y.T., and A.M.; Visualisation, R.F.L. and M.T.; Supervision, M.T., T.Y., and A.M.; Project Administration, M.T.; Funding Acquisition, M.T., and Y.T. All authors have read and agreed to the published version of the manuscript.

Funding: This research was funded by the South African Department of Science and Technology (DST) under the Nanotechnology Health, Safety and Environment Risk Research Platform (grant number: 0085/2015).

Institutional Review Board Statement: Not applicable.

Informed Consent Statement: Not applicable.

Data Availability Statement: The data presented is available on request from the corresponding author.

Conflicts of Interest: The authors declare no conflict of interest.

Sample Availability: Samples of the compounds are available from the authors.

\section{References}

1. Philippe, A.; Košík, J.; Welle, A.; Guignier, J.M.; Clemens, O.; Schaumann, G.E. Extraction and characterization methods for titanium dioxide nanoparticles from commercialized sunscreens. Environ. Sci. Nano 2018, 5, 191-202. [CrossRef]

2. Benítez-Martínez, S.; López-Lorente, Á.I.; Valcárcel, M. Determination of $\mathrm{TiO}_{2}$ nanoparticles in sunscreen using N-doped graphene quantum dots as a fluorescent probe. Microchim. Acta 2016, 183, 781-789. [CrossRef]

3. Nthwane, Y.B.; Tancu, Y.; Maity, A.; Thwala, M. Characterisation of titanium oxide nanomaterials in sunscreens obtained by extraction and release exposure scenarios. SN Appl. Sci. 2019, 1, 312. [CrossRef]

4. Bairi, V.G.; Lim, J.-H.; Fong, A.; Linder, S.W. Size characterization of metal oxide nanoparticles in commercial sunscreen products. J. Nanopart. Res. 2017, 19, 256. [CrossRef]

5. Benn, T.; Westerhoff, P. Nanoparticle Silver Released into Water from Commercially Available Sock Fabrics. Environ. Sci. Technol. 2008, 42, 4133-4139. [CrossRef] [PubMed]

6. CEM. MARS Microwave Digestion-Sample Preparation Using Microwave Digestion. Available online: http://cem.com/ microwave-digestion (accessed on 16 July 2018).

7. Silva, F.L.; Duarte, T.A.; Melo, L.S.; Ribeiro, L.P.; Gouveia, S.T.; Lopes, G.S.; Matos, W.O. Development of a wet digestion method for paints for the determination of metals and metalloids using inductively coupled plasma optical emission spectrometry. Talanta 2016, 146, 188-194. [CrossRef] [PubMed]

8. De La Calle, I.; Menta, M.; Séby, F. Current trends and challenges in sample preparation for metallic nanoparticles analysis in daily products and environmental samples: A review. Spectrochim. Acta Part B At. Spectrosc. 2016, 125, 66-96. [CrossRef]

9. Virkutyte, J.; Al-Abed, S.R.; Dionysiou, D.D. Depletion of the protective aluminum hydroxide coating in $\mathrm{TiO}_{2}$-based sunscreens by swimming pool water ingredients. Chem. Eng. J. 2012, 191, 95-103. [CrossRef] 
10. Al-Abed, S.R.; Virkutyte, J.; Ortenzio, J.N.R.; McCarrick, R.M.; Degn, L.L.; Zucker, R.; Coates, N.H.; Childs, K.; Ma, H.; Diamond, S.; et al. Environmental aging alters $\mathrm{Al}(\mathrm{OH})_{3}$ coating of $\mathrm{TiO}_{2}$ nanoparticles enhancing their photocatalytic and phototoxic activities. Environ. Sci. Nano 2016, 3, 593-601. [CrossRef]

11. Auffan, M.; Pedeutour, M.; Rose, J.; Masion, A.; Ziarelli, F.; Borschneck, D.; Chanéac, C.; Botta, C.; Chaurand, P.; Labille, J.; et al. Structural Degradation at the Surface of a $\mathrm{TiO}_{2}$-Based Nanomaterial Used in Cosmetics. Environ. Sci. Technol. 2010, 44, $2689-2694$. [CrossRef]

12. Labille, J.; Feng, J.; Botta, C.; Borschneck, D.; Sammut, M.; Cabie, M.; Auffan, M.; Rose, J.; Bottero, J.-Y. Aging of TiO 2 nanocomposites used in sunscreen. Dispersion and fate of the degradation products in aqueous environment. Environ. Pollut. 2010, 158, 3482-3489. [CrossRef] [PubMed]

13. Lewicka, Z.A.; Benedetto, A.F.; Benoit, D.N.; Yu, W.W.; Fortner, J.D.; Colvin, V.L. The structure, composition, and dimensions of $\mathrm{TiO}_{2}$ and $\mathrm{ZnO}$ nanomaterials in commercial sunscreens. J. Nanopart. Res. 2011, 13, 3607-3617. [CrossRef]

14. Jeon, S.-K.; Kim, E.-J.; Lee, J.; Lee, S. Potential risks of $\mathrm{TiO}_{2}$ and $\mathrm{ZnO}$ nanoparticles released from sunscreens into outdoor swimming pools. J. Hazard. Mater. 2016, 317, 312-318. [CrossRef] [PubMed]

15. Dan, Y.; Shi, H.; Stephan, C.; Liang, X. Rapid analysis of titanium dioxide nanoparticles in sunscreens using single particle inductively coupled plasma-mass spectrometry. Microchem. J. 2015, 122, 119-126. [CrossRef]

16. Lorenz, C.; Tiede, K.; Tear, S.; Boxall, A.; Von Goetz, N.; Hungerbühler, K. Imaging and Characterization of Engineered Nanoparticles in Sunscreens by Electron Microscopy, under Wet and Dry Conditions. Int. J. Occup. Environ. Health 2010, 16, 406-428. [CrossRef] [PubMed]

17. Sysoltseva, M.; Winterhalter, R.; Wochnik, A.S.; Scheu, C.; Fromme, H. Electron microscopic investigation and elemental analysis of titanium dioxide in sun lotion. Int. J. Cosmet. Sci. 2017, 39, 292-300. [CrossRef]

18. Hanigan, D.; Truong, L.; Schoepf, J.; Nosaka, T.; Mulchandani, A.; Tanguay, R.L.; Westerhoff, P. Trade-offs in ecosystem impacts from nanomaterial versus organic chemical ultraviolet filters in sunscreens. Water Res. 2018, 139, 281-290. [CrossRef]

19. Moeta, P.J.; Wesley-Smith, J.; Maity, A.; Thwala, M. Nano-enabled products in South Africa and the assessment of environmental exposure potential for engineered nanomaterials. SN Appl. Sci. 2019, 1, 577. [CrossRef]

20. Tyner, K.M.; Wokovich, A.M.; Doub, W.H.; Buhse, L.; Sung, L.-P.; Watson, S.S.; Sadrieh, N. Comparing methods for detecting and characterizing metal oxide nanoparticles in unmodified commercial sunscreens. Nanomedicine 2009, 4, 145-159. [CrossRef]

21. Lu, P.-J.; Huang, S.-C.; Chen, Y.-P.; Chiueh, L.-C.; Shih, D.Y.-C. Analysis of titanium dioxide and zinc oxide nanoparticles in cosmetics. J. Food Drug Anal. 2015, 23, 587-594. [CrossRef]

22. Sharma, S.; Sharma, R.K.; Gaur, K.; Torres, J.F.C.; Loza-Rosas, S.A.; Torres, A.; Saxena, M.; Julin, M.; Tinoco, A.D. Fueling a Hot Debate on the Application of $\mathrm{TiO}_{2}$ Nanoparticles in Sunscreen. Materials 2019, 12, 2317. [CrossRef] [PubMed]

23. Pulvin, S.; Tanvir, S.; Anderson, W.A. Toxicity Associated with the Photo Catalytic and Photo Stable Forms of Titanium Dioxide Nanoparticles Used in Sunscreen. MOJ Toxicol. 2015, 1, 78-94. [CrossRef]

24. Mitrano, D.M.; Motellier, S.; Clavaguera, S.; Nowack, B. Review of nanomaterial aging and transformations through the life cycle of nano-enhanced products. Environ. Int. 2015, 77, 132-147. [CrossRef] [PubMed]

25. Pulit-Prociak, J.; Chwastowski, J.; Kucharski, A.; Banach, M. Functionalization of textiles with silver and zinc oxide nanoparticles. Appl. Surf. Sci. 2016, 385, 543-553. [CrossRef]

26. Buşilă, M.; Musat, V.; Textor, T.; Mahltig, B. Synthesis and characterization of antimicrobial textile finishing based on Ag:ZnO nanoparticles/chitosan biocomposites. RSC Adv. 2015, 5, 21562-21571. [CrossRef]

27. Zhang, G.; Liu, Y.; Gao, X.; Chen, Y. Synthesis of silver nanoparticles and antibacterial property of silk fabrics treated by silver nanoparticles. Nanoscale Res. Lett. 2014, 9, 216. [CrossRef]

28. Zhang, D.; Toh, G.W.; Lin, H.; Chen, Y. In situ synthesis of silver nanoparticles on silk fabric with PNP for antibacterial finishing. J. Mater. Sci. 2012, 47, 5721-5728. [CrossRef]

29. Zhang, F.; Wu, X.; Chen, Y.; Lin, H. Application of silver nanoparticles to cotton fabric as an antibacterial textile finish. Fibers Polym. 2009, 10, 496-501. [CrossRef]

30. Lorenz, C.; Windler, L.; Von Goetz, N.; Lehmann, R.P.; Schuppler, M.; Hungerbühler, K.; Heuberger, M.; Nowack, B. Characterization of silver release from commercially available functional (nano)textiles. Chemosphere 2012, 89, 817-824. [CrossRef]

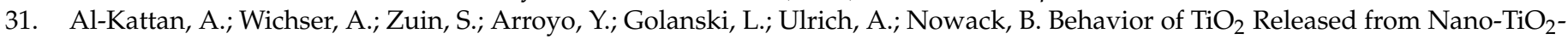
Containing Paint and Comparison to Pristine Nano-TiO 2 . Environ. Sci. Technol. 2014, 48, 6710-6718. [CrossRef]

32. Al-Kattan, A.; Wichser, A.; Vonbank, R.; Brunner, S.; Ulrich, A.; Zuin, S.; Nowack, B. Release of $\mathrm{TiO}_{2}$ from paints containing pigment- $\mathrm{TiO}_{2}$ or nano- $\mathrm{TiO}_{2}$ by weathering. Environ. Sci. Process. Impacts 2013, 15, 2186. [CrossRef] [PubMed]

33. Samontha, A.; Shiowatana, J.; Siripinyanond, A. Particle size characterization of titanium dioxide in sunscreen products using sedimentation field-flow fractionation-inductively coupled plasma-mass spectrometry. Anal. Bioanal. Chem. 2011, 399, 973-978. [CrossRef] [PubMed]

34. Contado, C.; Pagnoni, A. $\mathrm{TiO}_{2}$ in Commercial Sunscreen Lotion: Flow Field-Flow Fractionation and ICP-AES Together for Size Analysis. Anal. Chem. 2008, 80, 7594-7608. [CrossRef] [PubMed]

35. Foltête, A.-S.; Masfaraud, J.-F.; Bigorgne, E.; Nahmani, J.; Chaurand, P.; Botta, C.; Labille, J.; Rose, J.; Férard, J.-F.; Cotelle, S. Environmental impact of sunscreen nanomaterials: Ecotoxicity and genotoxicity of altered $\mathrm{TiO} 2$ nanocomposites on Vicia faba. Environ. Pollut. 2011, 159, 2515-2522. [CrossRef] [PubMed] 
36. Cascio, C.; Geiss, O.; Franchini, F.; Ojea-Jiménez, I.; Rossi, F.; Gilliland, D.; Calzolai, L. Detection, quantification and derivation of number size distribution of silver nanoparticles in antimicrobial consumer products. J. Anal. At. Spectrom. 2015, 30, 1255-1265. [CrossRef]

37. Wasukan, N.; Srisung, S.; Kulthong, K.; Boonrungsiman, S.; Maniratanachote, R. Determination of silver in personal care nanoproducts and effects on dermal exposure. J. Nanopart. Res. 2015, 17, 1-11. [CrossRef]

38. De Leersnyder, I.; Rijckaert, H.; De Gelder, L.; Van Driessche, I.; Vermeir, P. High Variability in Silver Particle Characteristics, Silver Concentrations, and Production Batches of Commercially Available Products Indicates the Need for a More Rigorous Approach. Nanomaterials 2020, 10, 1394. [CrossRef]

39. Mackevica, A.; Olsson, M.E.; Hansen, S.F. Quantitative characterization of $\mathrm{TiO}_{2}$ nanoparticle release from textiles by conventional and single particle ICP-MS. J. Nanopart. Res. 2018, 20, 6. [CrossRef]

40. Windler, L.; Lorenz, C.; Von Goetz, N.; Hungerbühler, K.; Amberg, M.; Heuberger, M.; Nowack, B. Release of Titanium Dioxide from Textiles during Washing. Environ. Sci. Technol. 2012, 46, 8181-8188. [CrossRef]

41. Bentlin, F.R.S.; Pozebon, D.; Mello, P.A.; Flores, É.M.M. Determination of trace elements in paints by direct sampling graphite furnace atomic absorption spectrometry. Anal. Chim. Acta 2007, 602, 23-31. [CrossRef]

42. De La Calle, I.; Menta, M.; Klein, M.; Séby, F. Screening of $\mathrm{TiO}_{2}$ and Au nanoparticles in cosmetics and determination of elemental impurities by multiple techniques (DLS, SP-ICP-MS, ICP-MS and ICP-OES). Talanta 2017, 171, 291-306. [CrossRef] [PubMed]

43. Bocca, B.; Caimi, S.; Senofonte, O.; Alimonti, A.; Petrucci, F. ICP-MS based methods to characterize nanoparticles of TiO 2 and $\mathrm{ZnO}$ in sunscreens with focus on regulatory and safety issues. Sci. Total Environ. 2018, 630, 922-930. [CrossRef] [PubMed]

44. Mozhayeva, D.; Engelhard, C. A critical review of single particle inductively coupled plasma mass spectrometry-A step towards an ideal method for nanomaterial characterization. J. Anal. At. Spectrom. 2020, 35, 1740-1783. [CrossRef]

45. Flores, K.; Turley, R.S.; Valdes, C.; Ye, Y.; Cantu, J.; Hernandez-Viezcas, J.A.; Parsons, J.G.; Gardea-Torresdey, J.L. Environmental applications and recent innovations in single particle inductively coupled plasma mass spectrometry (SP-ICP-MS). Appl. Spectrosc. Rev. 2019, 1-26. [CrossRef]

46. Mitrano, D.M.; Lombi, E.; DaSilva, Y.A.R.; Nowack, B. Unraveling the Complexity in the Aging of Nanoenhanced Textiles: A Comprehensive Sequential Study on the Effects of Sunlight and Washing on Silver Nanoparticles. Environ. Sci. Technol. 2016, 50, 5790-5799. [CrossRef]

47. Laborda, F.; Jiménez-Lamana, J.; Bolea, E.; Castillo, J.R. Selective identification, characterization and determination of dissolved silver(i) and silver nanoparticles based on single particle detection by inductively coupled plasma mass spectrometry. J. Anal. At. Spectrom. 2011, 26, 1362-1371. [CrossRef]

48. Mitrano, D.M.; Lesher, E.K.; Bednar, A.; Monserud, J.; Higgins, C.P.; Ranville, J.F. Detecting nanoparticulate silver using single-particle inductively coupled plasma-mass spectrometry. Environ. Toxicol. Chem. 2012, 31, 115-121. [CrossRef]

49. Bustos, A.R.M.; Petersen, E.J.; Possolo, A.; Winchester, M.R. Post hoc Interlaboratory Comparison of Single Particle ICP-MS Size Measurements of NIST Gold Nanoparticle Reference Materials. Anal. Chem. 2015, 87, 8809-8817. [CrossRef]

50. Laborda, F.; Bolea, E.; Jiménez-Lamana, J. Single Particle Inductively Coupled Plasma Mass Spectrometry: A Powerful Tool for Nanoanalysis. Anal. Chem. 2014, 86, 2270-2278. [CrossRef]

51. Liu, J.; Murphy, K.E.; Winchester, M.R.; Hackley, V.A. Overcoming challenges in single particle inductively coupled plasma mass spectrometry measurement of silver nanoparticles. Anal. Bioanal. Chem. 2017, 409, 6027-6039. [CrossRef] 